Portland State University

PDXScholar

5-10-1996

\title{
An Assessment of the Needs of International Students for Student Services at Southern Oregon State College
}

Molly K. Emmons

Portland State University

Follow this and additional works at: https://pdxscholar.library.pdx.edu/open_access_etds

Part of the Bilingual, Multilingual, and Multicultural Education Commons Let us know how access to this document benefits you.

Recommended Citation

Emmons, Molly K., "An Assessment of the Needs of International Students for Student Services at Southern Oregon State College" (1996). Dissertations and Theses. Paper 5076.

https://doi.org/10.15760/etd.6950

This Thesis is brought to you for free and open access. It has been accepted for inclusion in Dissertations and Theses by an authorized administrator of PDXScholar. Please contact us if we can make this document more accessible: pdxscholar@pdx.edu. 


\section{THESIS APPROVAL}

The abstract and thesis of Molly K. Emmons for the Master of Arts in TESOL were presented May 10, 1996, and accepted by the thesis comittee and the department.

COMMITTEE APEROVALS:

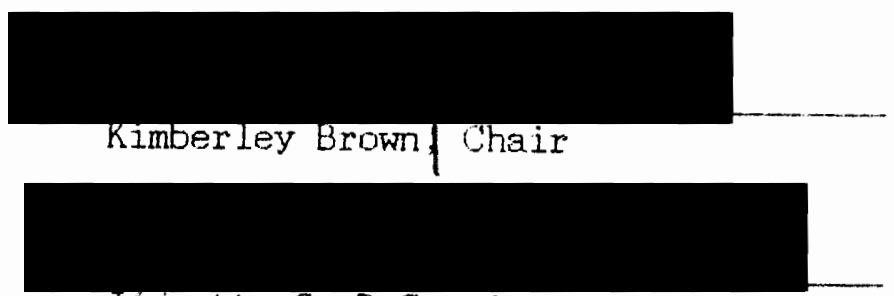

Jeanette S. DeCarrico

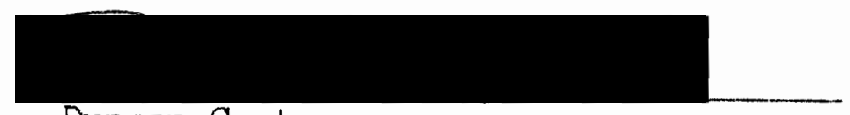

Duncan Carter

Representative of the office of

Graduate Studies

DEPARTMENT APPROVAL:

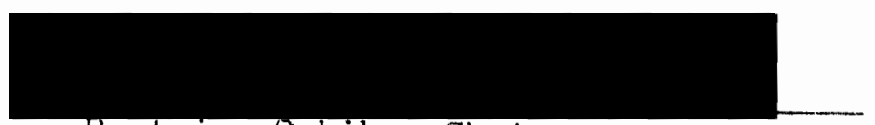

Beatrice Ushika, Chair

Department of Applied Linguistics

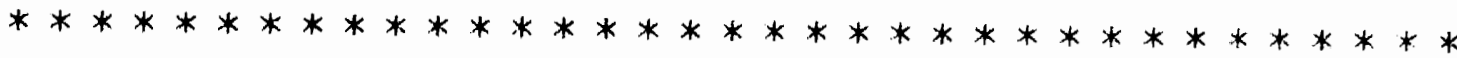

ACCEPTED FOR PORTLAND STATE UNTUERSITY BY THE LIBRARY

by

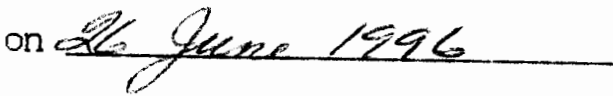


AN ABSTRACT OF THE THESIS OF MOIly $\mathrm{K}$. Emmons for the Master of Arts in TESOL presented on May 10, 1996.

Title: AN ASSESSMENT OF THE NEEDS OF INTERNATIONAL STUDENTS FOR GTUDENT SERVICES AT SOUTHERN OREGON STATE COLIEGE

International students at our institutions of higher education have educational and personal needs which extend beyond the classroom. These needs are supposedly provided for by student personnei services, but little data has been collected which examines how international students use student services, and if their use differs significantly from use by American students. If their perceptions of students services and use of these resources does differ, what does that signify?

This study measures the use and perceptions of student services by international and American students at Southern Oregon State College. Twenty-one philosophical objectives were examined for levels of importance, effectiveness, and resultant need. A list of twenty resources at the College were compiled and respondents were asked to rate the helpfulness of each resource. Demographic data on students included residence, length of time on campus, involvement in extracurricular activities, and other characteristics and was compared to knowledge of student services resources. International students were asked to identify their English language proficiency and this was compared with their need for student services 
objectives.

All three hypotheses that there would te no differenos hetween American and international students in their peroeptions of the importance, effectiveness, and helpfulness of student services were rejected at the .05 level of significance. International students found three objectives to be ineffective, and the focus of these objectives suggested that cultural differences may contribute to student problems. A correlation between self-reported Enslish language proficiency and satisfaction of needs for student services objectives was noted, while no relationship between TOEFL score and satisfaction of needs was found.

Southern Oregon State College may want to reconsider its orientation procedures in light of the number of "don 't know" responses from students when asked about a variety of student services. Awareness of student services and the effectiveness of those services for both American and international students are issues which this study aims to help the college address. 
AN ASSESSMENT OF THE NEEDS OF INTERNATIONAL STUDENTS FOR STUDENT SERVICES AT SOUTHERN OREGON STATE COLLEGE

by

MOLLY K. EMMONS

A thesis submitted in partial fulfillment of the requirements for the degree of

\author{
MASTER OF ARTS \\ in \\ TESOL
}

\title{
Portland State University
} 1996 
EREEACE AND ACXNOWLEDFFMENTS

The thesis that follows has charted an intricate course. far from what I first imagined it to be. My original. interest was in the academic experiences of international students outside of thein olassronms which oaused them difficulty. I focused on thair experiences in tutoring situations and determined that I woll research whether more plentiful and sophisticoted tutoring was indicated.

This led me to the proposed Writing Center at the University of Portland, where I was an instructor, and where an ESL component was planned. I proposed to use a faculty survey to discover which academio and other difficulties of international students oon bo identified for the purpose of designing the ESL tutoring oomponent..

After an extended hiatus (four years) I resumed work on my thesis only to discover that the Writing Center--and its ESL component--were up and running and had been for two years. What followed was a perplexing attempt to salvage my foundering thesis.

I went back to my original area of focus to delve into what had interested me to begin with. I realized that I wanted to foous on the needs of international students outside of their classes. As an ESL instructor for the last seven years, I have served time and again in the capacity of advisor and counselor to international students who are lost in the American college environment. These students lacked information about resources available to them on campus; I 
decided to focus my study in this area. I feel this study provides important information about how international students perceive and use student services as well as the extent of their knowledge of student resources, especially in comparison with American students.

I am extremely grateful for the learning opportunity which has come my way in the writing of this thesis. I teach my freshman composition students that good writing has "resonance"; like a stone dropped in a pool, it must create ripples which spread out. from itself to touch others and it must receive those same ripples back again. I can sincerely state that this thesis has created and undergone that effect. Many individuals can account for this clain. The faculty in the Department of Applied Linguistics at Portland State University have experienced my trials with oreating a successful study and have implemented policy changes as a result of them. My thesis advisor, thesis committee, and the excellent personnel in the Graduate Studies Office have graciously stretched all boundaries to allow me every opportunity for success despite multiple obstacles which seemed to pile themselves perversely upon my efforts. I have learned as much from my personal interactions in this process as I have from any other facet of my work.

This thesis has resonated into the composition courses I teach at Rogue Community College. My students more fully understand the idea behind primary research; I have taught them firsthand how to research literature and use the library resources. Several of my students are emotionally invested in the success of my thesis. 
This thesis has resonated onto the campus at Southern Oregon State College, where I conducted the study with the help of former colleagues and new friends. Administrative personnel are anticipating receiving the results of the study.

This thesis has resonated strongly in my personal life, in my relationship with my family, my husband and son, my mother and father. My friends as well have become interested and involved as I have struggled over the last several months to create a study of worth. All of their efforts, their patience, their support are integral to any success I may achieve.

This thesis resonates most strongly within me. My sense of self-esteem has plummeted and soared with my writing experiences, and I am a stronger and more learned person for having undergone every difficulty. I have forged within myself a determination and desire I didn't know I possessed. I have found courage and fortitude which have gone unneeded for many long years.

Conducting this study and writing this thesis has affected every aspect of my life--all for the better, I realize. I have also come to realize that knowledge arrives in great and painful bursts sometimes, and that too resonates. I have been the amazed recipient. of several such bursts of knowledge in my journey toward completing a master's degree. It is my fervent hope that the reading of this thesis will resonate a small amount of that knowledge to others. Molly Emmons April 1996 
TABLE OF CONTENTS

EAGE

PREFACE AND ACKNONLELGEMENTS . . . . . . . . . . . . . . . . . iii

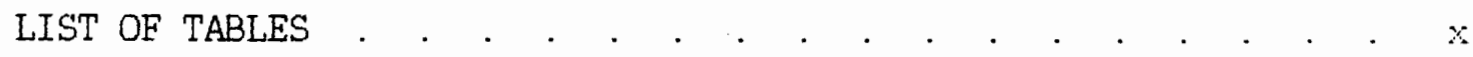

CHAPTER

I INTLOUUCTION . . . . . . . . . . . . . . 1

Purpose of a College Education . . . . . 3 3

Definition of Student Services. . . . . . 3

Statement of the Problen . . . . . . . . 4

Purpose . . . . . . . . . . . . 6

Significance of the Study . . . . . . . 8

Method of the Study . . . . . . . . . 9

Single Institution Study . . . . . . . . 10

Limitations . . . . . . . . . . . . 11

II REVIEW OF THE LITERATURE . . . . . . . . . . . . . . 12

Purpose of the Literature Review . . . . . 12

Needs Assessment Survey Development . . . . 13

Studies of the Problems and Needs of
International Students

Academic Supports and Models . . . . . 17

English Language Proficiency Studies
Relating to Acadenic Success . . . . . . 18 
Population and Sample. . . . . . . . . 23

Data Collection. . . . . . . . . . 25

Instrument Development . . . . . . . . 28

Issues of Reliability and Validity . . . . 34

Piloting the Instrument . . . . . . . . 36

Treatment of the Data ... . . . . . . 37

"Importance" of Objectives . . . . . . . . 39

"Effectiveness" of Objectives . . . . . . 41

"Needs" of Students Regarding
Objectives . . . . . . . . . . . . . 43

"Helpfulness of Resources" . . . . . . . 45

English Language Proficiency Factor . . . . 47

IV RESULTS . . . . . . . . . . . . . . . . 49

Sample Returns . . . . . . . . . . . 50

Importance of Objectives . . . . . . . . . 50

Differences between International

and American Students..... . . . 51

Rank Order Interpretations for

Each Group and a Comparison

Between the Two Groups . . . . . . 51

Demographic characteristics . . . . . 56

Effectiveness of Objectives . . . . . . . . 56

Differences between International

and American Students . . . . . . . 57

Rank Order Interpretations . . . . . 61 
International Students . . . . . . 61

Anerican Students . . . . . . . . $6 \%$

Comparison of the 'lwo Groups . . . . 35

Demographic Characteristics . . . . . $6 E$

Needs of Students . . . . . . . . . . . 68

International Students . . . . . . 86

American Students . . . . . . . . 67

Comparison of Anerican and

Internationaj. Students Regarding

Helpfulness of Resources. . . . . . . . 71

Differences between American and

International Students . . . . . . 71

Rank Order Differences for American

and International Students and a

Comparison of Both. . . . . . . . 72

Student listed resources . . . . . . 75

Demographic Characteristics . . . . . 78

English Language Proficiency . . . . . . 81

Sumnary of Findings . . . . . . . . . 83

$\mathrm{V} \quad$ DISCUSSION $. \quad . \quad . \quad . \quad . \quad . \quad . \quad . \quad . \quad . \quad . \quad . \quad . \quad .87$

Findings . . . . . . . . . . . . . 88

Importance of Objectives . . . . . . 88

Effectiveness of Objectives . . . . . 89

Needs of Students . . . . . . . . . . 91

Helpfulness of Resources . . . . . . 92

Demographic Characteristics . . . . . 93 
English Languase Proficiency . . . . 94

Conclusions and Implications . . . . . . . 94

Comprarison of Results with Agler Study . . . 98

Recommendations . . . . . . . . . . . 99

Limitations . . . . . . . . . . . . 101

Suggestions for Revision of the

Questionnaire . . . . . . . . . . . 104

Suggestions for Further Research . . . . . 100

REFERENCES . . . . . . . . . . . . . . . . . . 108

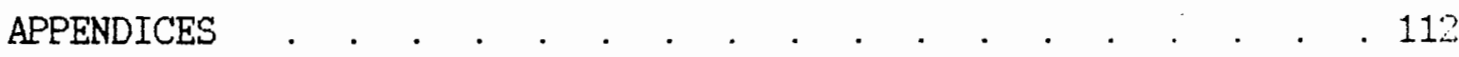

A Student Services Questionnaire . . . . . . 113

B Respondent Debriefing Letter. . . . . . . 123

C Table XIV, American and International.

Student Demographic Data . . . . . . . . 125 


\section{LYT OF TALES}

TAEIE

$\mathrm{APE}$

I. Significant Differences of Ferceptions of

Importance and Effectiveness of Objectives by Respondent Groups

II International Student Perceptions of Importance of Objectives by Rank Order

III American Student Perceptions of Importance of Objectives by Rank Order

IV International Student Perceptions of Effectiveness of Objectives by Rank Order

V American Student Perceptions of Effectiveness of Objectives by Rank Order

VI Needs of International Students by Rank Order

VII Needs of American Students by Rank Order

VIII Significant Differences Between American and International Students of Perceptions of Helpfulness of Available Resources

IX International Student Perceptions of Resources by Rank Order

X American Student Perceptions of Resources by Rank Order

XI Demographic Comparison of International and American Students by Knowledge of Resources

XII Relation Between Self-Reported English Proficiency and Extent to Which Needs are Met for International Students

XIII Relation Between Self-Reported TOEFL Score and Extent to Which Needs are Met for International Students

XIV American and International Student Demographic Data 
CHAPTER I

INTRODUCTION

In 1992 I was hired by the English Department at Southern Oregon State College to teach a variety of composition and literature courses. My offer of employment was based on an old resume which did not include information pertaining to my graduate studies in Applied Linguistics in the field of teaching English to speakers of other languages (TESOL). When I informed the department of my training, I was almost immediately considered for a position as an ESL specialist teaching composition courses restricted to ESL students. At SOSC, as well as at many other American institutions of higher learning, fully admitted international students are tested by a combination of discrete grammar questions and a holistically-graded composition. Those who fail to achieve the standard for freshman composition (Writing 121 at Oregon's public colleges) are placed in the Writing 101, 102, 103 series or its equivalent. These three classes currently (Spring 1996) enroll more than 25 percent of the admitted international students on the SOSC campus; these are students who have passed the Test of English as a Foreign Language (TOEEL).

As a concurrent employee of the American Language Academy, which serves as an English language institute for Southern Oregon State College, I was in an excellent position to observe international students as they completed the highest level of English language classes and made the transition to regularly admitted status 
at the college. At the time, I was the only employee who worked in both capacities as an ALA instructor and as a regular instructor at the college. As a result, I was asked to lecture each quarter to the assembled ALA students about the coming challenges and difficulties they would face as American college students.

In short, I was amazed by what these students did not know. As they were likely to enter regular status at SOSC at the beginning of any quarter, chances were quite high that they would not go through freshman orientation, which is offered only at the beginning of each academic year. As may be expected, they were unfamiliar with many American college classroom procedures and with most of the resources and personnel. In some cases my lecture was the only orientation these students received. As I fielded the same questions term after term during these lectures, I became apprehensive about the experience these students-and any international students coming to a new American campus--would have. They clearly had the ability and the ambition, but they needed knowledge about the resources available to them.

American students face many of these same problems as they begin their college careers. But the difficulties of international students are compounded by the language proficiency factor as well as several others--cultural, religious, even technological. Although they are entitled to the same richness in a college experience as American students, it is possible that this experience becomes unduly restricted to knowledge imparted in the course work. 
Purpose of a college education

The goals of higher education go beyond the intellectual to the personal development of students. MeIntyre (1975) indicates that an effective student personnel program can be instrumental in achieving a community spirit and high student morale. It is "not a matter of convenience or luxury; it is a matter of necessity" (61). Agler (1980) adds that student personnel services and instructional services together form the educational program of an institution. International students and American students have equal access to both instructional and student personnel services when they are admitted to institutions of higher education; if a lack of community spirit and low student morale is detected in the international student group as a whole, both student personnel services and instructional services should be examined as factors.

\section{Definition of student services}

Student personnel services can be defined in several ways. These include the philosophical point of view of student personnel, as well as the philosophy of student development. Another essential feature of student personnel services is the functions or services which may be coordinated by personnel workers under the direction of the college. These functions vary according to the particular needs of different institutions. College and university bulletins may be used to determine which services are provided at a particular 
institution. From these, lists can be compiled which represent

services offered by most colleges and universities. In this study, which focuses on Southern Oregon State College, these include:

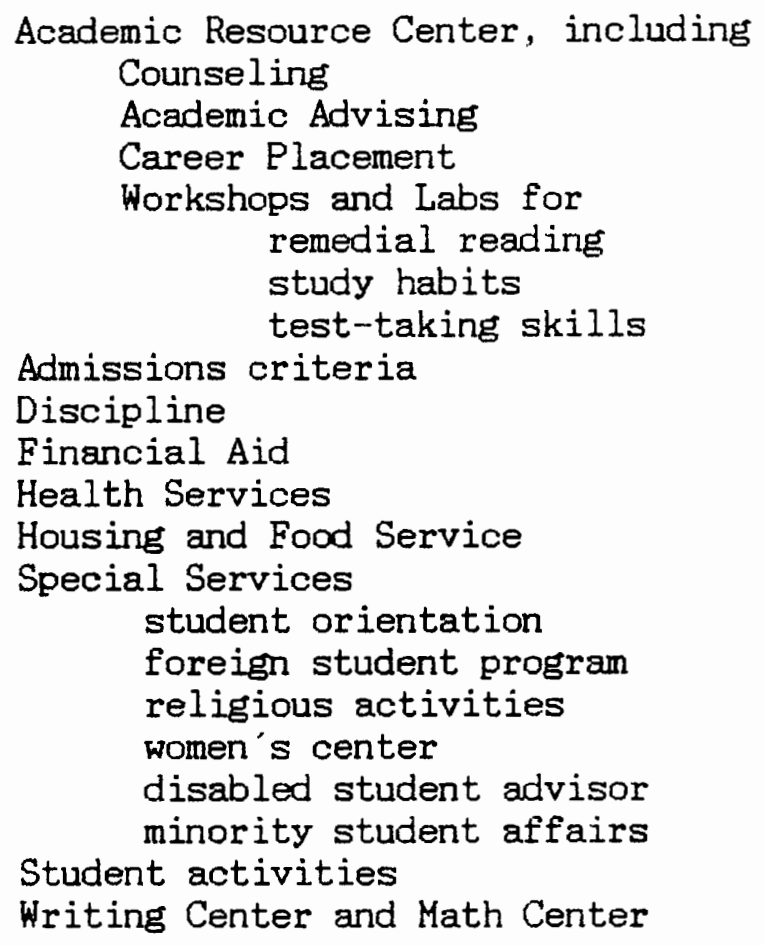

Statement of the problem

The majority of students . . . arrive in the United States with very little idea of the organization of American institutions of higher education, let alone with an understanding of the cultural adjustment problems they will face (Lee et al., 1981, x).

International students who have been fully admitted to the college are presumed to have undergone the same orientation procedure as American students and to be aware of the variety of student services offered. But are they using the services to the same extent 
as American students? If not, is language proficiency affecting their use of student services?

With the growing diversity of student backgrounds during recent years, there is a need to re-evaluate student services programs in order to adequately meet the needs of the students. According to Joan Jackson, Associate Dean of Students at Southern Oregon State College, a campus-wide survey currently being conducted in preparation for accreditation in the 1996-97 academic year is being used for the purpose of gathering raw data on all aspects of the student experience. The College Outcomes Survey (1995) being used includes a section on use of student services. Jackson points out the importance of basing evaluations on raw data rather than on unmeasured assumptions as had been done in the past. This is no longer acceptable to administrators at SOSC. According to Jackson: "We can't keep relying on what's always been done."

There have been few efforts to determine whether the needs of international students are being met by student personnel services, as regards the extent of their use of existing services. Even the accreditation survey for SOSC will not provide data in this area. One SOSC student (Tanaka 1994) did conduct an independent survey of intermational students at the college in which questions about use and awareness of the counseling services at SOSC were included. Tanaka found that 63 of the 91 international students surveyed were not aware of the counseling services. As a result, counselors in the Academic Resource Center at SOSC are creating and promoting a new 
group counseling session to be held regularly for international students. This lack of awareness supports the hypothesis that international students do not use student services to the extent that they are used by American students at SOSC. The response by the counselors indicates an openness to revising existing programs in the area of student services based on new data. Further surveying of students may provide data for further positive changes if they are indicated.

\section{Burpose}

If the personnel at an institute of higher education who work with international students become concerned about the performance of those students, they must examine a variety of factors to determine which are having a negative effect. In addition to the instruction itself and the abilities of the individual students, an important component of the college experience is the services provided outside of the classroom.

College instructors at Southern Oregon State College, consistent with faculty at other institutions, have complained that international students are not performing at the level of American students. Many of the international students themselves admit that they are having a number of difficulties with their college experience; these are common complaints at American colleges. "Difficulties are expected," says Johnson (1971), "and consequently programs and university personnel are often provided to ease the 
adiustment process" (61). To determine whether and to what extent the use of student personnel services by international students is a major contributing factor, the general literature pertainine to assessment both of the needs of international students and of the use of student services should be explored, as well as literature describing studies of the use of student services by international students, if that is available. The conclusions made in these studies will help in making policy decisions regarding the education of international students. At Southern Oregon State College, international students have never been surveyed regarding their personnel needs, and previous studies have not been examined for data or conclusions which would suggest alternatives to the present procedures for answering those students needs.

To assess the use of services for students at Southern Oregon State College by international students, the following questions will be addressed in this study:

1. How important is each objective of Student Services at Southern Oregon State College for international students when compared to American students?

2. How effectively is each objective performed at Southern Oregon State College for international students when compared to American students?

3. To what extent are the various objectives performed as needed as Southern Oregon State College? These needs emerge out of the perceived importance and effectiveness of objectives. 
4. How helpful are the resources available to students outside the classroom at Southern Oregon State College?

5. To what extent do American college students differ from international students in their use of student services at Southern Oregon State College?

6. Does English language proficiency play a role in the use of student services at Southern Oregon State College?

These questions will be examined through noting a variety of differences between the students. Selected questions will be examined by distributions of year in school, length of time at the college, English language proficiency, and extent of participation in extra-curricular activities.

\section{Significance of the study}

The objective is to determine the effectiveness of student services for international students at Southern Oregon State College and to identify needs that result from the effectiveness assessment. One of the tasks is to work with several segments of the college-including personnel services employees, deans, department heads, instructors, and the students themselves--to ensure that their perceptions of the basic objectives are compatible with each other. Including all constituencies leads to "improved understanding of the personnel point of view and of its potential contributions to institutional philosophy and activities" (Brunson 75).

This study will modify an instrument previously used primarily 
for assessing the effectiveness of student services for American students (Agler 1980). The instrument assesses not only the philosophical objectives of student services, but also assesses specific resources available to students outside the classroom. However, any relationships between specific objectives identified in Section I of the questionnaire and specific resources identified in Section II are not intended or identified. Most of the objectives correspond with facets of several resources.

\section{Method of the study}

International students must comprise some portion of the college students who use student services. Do they use the services as successfully as American students? One hypothesis to be tested is that international students are not using student services as much as American students. Utilizing a questionnaire developed for American students at the University of La Verne, a private parochial college in southern California, the use of and need for student services by international students can be compared to its use by American students at Southern Oregon State College. This questionnaire has been revised by having it examined for relevance by student services personnel at Southern Oregon State College, who determined which questions were not applicable and suggested additional student resources. After the questionnaire was revised, it was distributed in classrooms to groups of students at all levels from freshman to senior. Thirty percent of the international students at Southem 
Oregon State College are represented, all of whom are regularly admitted students who have passed an English language proficiency threshold. These international students were asked to report their last TOEFL test score and to label their own English language proficiency on a scale. Both measures have been indexed with the fulfilled and unfulfilled need of student services to determine if English language proficiency affects the use of student services. According to Lee et al. (1981), self-perceived English proficiency is a strong predictor of satisfaction in progress toward achieving both primary and secondary goals as well as in facilitating course work. It is important for international students to be confident about their language skills in order to interact with native speakers and compete in an academic program $(x v)$.

Single institution study

The single institution evaluation process was selected for this study. As Berry (1967) points out, "the only way to insure even approximate accuracy is to examine each campus in its own setting" (3).

Southern Oregon State College was selected because of its proximity to the researcher and because of its relatively high enrollment of international students (160, or $3.5 \%$ of the student population, which is the highest enrollment of international students at any college in southern Oregon). To combine data between varying institutions would "muddy the results" (Agler 13). The college also 
contracts its ESL program with the American Language Academy, which brings international students from a variety of cultures and countries and with a range of English language proficiency to the campus.

\section{Limitations}

The study is limited to respondents of the main campus who are officially enrolled at the college.

The study is limited to the perceptions of specified student services objectives identified in the questionnaire and is also limited to responses concerning the helpfulness of identified resources for students.

Since this study is descriptive only of Southern Oregon State College, generalization of findings beyond the college is unwarranted. 
CHAPTER II

REVIEW OF THE LITERATURE

\section{Purpose of the literature review}

What are the ways in which the use of student services by international students have been effectively measured? The answer to this question will provide the essential background to measuring the use of student services by international students at Southern Oregon State College. But before this question can be answered, its components must be examined. The concept of student services itself needs to be defined. In general, how have student personnel services been evaluated? What factors are involved in the college experience of international students which may be an important consideration of their use of student services? New research into the use of student services, particularly as it relates to international students, does

not come into existence from a vacuum of background information. The relevance of previous studies in these areas is discussed here.

This chapter presents a historical perspective of the evaluation of student personnel services in the United States, both in general and as it applies to international students; in this respect, the factor of language proficiency is taken into account. This review is divided into the development of survey and evaluation instruments, studies involving the problems and needs of 
international students, examination of some academic support programs and models, and a discussion of how academic success relates to language proficiency.

\section{Needs assessment survey development}

One early survey of student personnel services was conducted by Hopkins in 1926 and measured personnel procedures in five general areas at thirteen institutions of higher education. Cowley developed a survey in 1931 asking about nineteen personnel functions at the university, with a focus on whether the function was in need of development.

In 1932, Brumbaugh and Smith evaluated ten major divisions they found essential to personnel, developing a point scale with the assistance of experts in the area of student personnel work from a variety of colleges and universities.

Wrenn and Kamm (1948) constructed an Evaluation Report Form for student services at the University of Minnesota, focusing on fourteen personnel services which correspond remarkably closely with the services studied in the most recent surveys. This survey dealt with the administrative attitude toward the services. Kamm (1955) was the first to develop a student services evaluation which evaluated the students' point of view, to be used in conjunction with the survey created with Wrenn. The survey had 60 items and allowed students to respond with a "yes" to indicate that services were functioning adequately and a "no" if the service was inadequate. 
In 1962 Fitzgerald developed The Student Personnel Services Questionnaire which has been used extensively and in several modified forms in subsequent studies (Agler 1980). The survey contained forty statements and asked faculty for perceptions of specific personnel functions in terms of a range of the importance of each function.

McDavis (1974) developed a Survey of Student Personnel Objectives to determine whether an institution's student personnel services were achieving minimally essential objectives. The survey was divided into two sections; Part I asked if student personnel services were providing various services to help students, while Part II asked if student personnel services were actually assisting the students in various ways. Respondents could respond "yes," "no," or "don't know," and results indicated that the instrument could be used with diverse populations such as students, faculty, and administrators in evaluating the effectiveness of an institution's student personnel services.

Agler (1980) summarizes several single institution studies and has determined that since the Hopkins survey in 1926, eight instruments to evaluate student services have been developed and used in multiple surveys, with the Fitzgerald instrument used most frequently (43). Agler uses these studies in analyzing the definition of needs assessment. The most general definition is that of the process to be used in identifying "the gaps between what is and what ought to be" (22). Emphasis is put more on the respondent's perception of needs rather than the assessor's perception. Agler 
modified her needs assessment from the McDavis instrument so that there existed a comparison of "what is" (as quoted above) with "effectiveness" and "what ought to be" with "inportance" (underline added here for emphasis). That comparison is also made in the present study.

The present study continues the trend of surveying students while maintaining the range of personnel services established by some of the earliest studies. The most important change in the present study is that it compares the use of personnel services by American college students with the use of services by international students with the underlying assumption that international students have differing problems and needs.

\section{Studies of problems and needs of international students}

Hull (1978) and Flack (1976), after reviewing an extensive amount of literature, concluded that the major reasons international students came to the United States were the following: to get an advanced education or training not available at home, to acquire prestige through a degree from a U.S. institution, to take advantage of available scholarship funds, to escape unsettled political or economic conditions, and to learn more about the United States.

Lee et al. (1981) cited an unpublished study by Forrest G. Moore (1965) in which he suggested that dissatisfaction of international students with their American experience was with the specific details of college life and not the general college 
situation. Moore delineated the following international student problems: 1) problems related to proficiency in English; 2) problems caused by differences in the educational systems; 3) problems of adjustment to the American culture; 4) problems related to the complexity of the situation in terms of the number of adjustments required and the time allowed for making them; 5) problems of legal impediments to study abroad; 6) problems of academic performance; 7) problems of inadequate resources; and 8) problems of social adjustment.

Securing good acadenic advice, financial difficulty, insufficient orientation, and lack of social and personal guidance were found to be the major problems by Ursua (1969). Johnson (1971) suggested, by comparing responses of international students and those of American students, that the academic problems of both international students and American students were basically the same except for the language problem.

Lee et al.'s (1981) extensive review of studies measuring problems faced by international students revealed that many found inadequacies related to areas covered in student services.

The problems and needs of an international student seem to change over time. Klein et al. (1971) reported that early problems were those associated with loneliness, followed by academic problems, and later by emotional and interpersonal problems. They also found that self-confidence was a major factor in meeting social needs of international students. They suggested a shift be made from concern 
with the foreign aspect of international students to the aspects shared by all students.

Walter (1978) states that the use of counseling services by international students has been minimal, because American counselors have not been trained to provide effective support for them.

The problems and needs of international students may be grouped into three main themes. Lack of language proficiency as the recurring problem is cited throughout the history of these studies. A variety of other problems and needs specific to international students have been identified. But another, humanistic theme emerges in the later studies discussed above which focuses on the similarities between American and international students--even in the area of their problems. For this reason, the use of student services by international students compared to American students is especially relevant. If language proficiency is a determining factor in the use of student services by international students, then a stronger link is forged between the language-based findings of the earlier studies and the more humanistic themes of the later studies.

Yet those problems and needs of international students which are peculiar to them are recognized in our institutions of higher education, as demonstrated by the support programs provided for then.

\section{Academic support proerams and models}

Support services in the form of counseling, workshops, tutors, writing centers, protected courses, etc. are offered to help 
international students in universities across the united states. Nevertheless, Snow and Brinton (1988) say that "what is accurring is that the university system is generally unprepared to assist [international] students in attaining academic success by providing the necessary support system" (554). They ask educators to recognize what students need to be able to do at a university in order to prepare then to meet academic demands.

Hargett and Olswang (1984), having noted the problems the University of Washington was having with international students who had been admitted relying on English proficiency exams, suggest a variety of support services in addition to raising the minimum TOEFL level for full-time unrestricted admission to 580 . These support services include asking faculty to take a more humanitarian aperoach to teaching international students. Hargett and Olswang feel this approach is particularly suited to the small liberal arts college, which is characterized by personalized instruction and individualized services.

No matter how sensitive a college is to the needs of the international student, the hurdle of language proficiency must be passed, and where this hurdle is placed (and how high it should be, and even how many there should be) is of some debate. How connected is it with the other problems encountered by international students?

English language proficiency studies relating to academic success The majority of the research findings agree that proficiency in 
English is positively related to academic performance (Lee et al. 1980, 13). Lack of proficiency with English is often thought of as the source of international student social problems. Morris (1960) found that difficulty with English was negatively related to international students' satisfaction with their stay and contact with U.S. nationals. Nenyod (1975) concluded that some social, housing, and food problems were due to lack of proficiency in English. Spaulding and Flack (1976) concluded that students who had difficulties with oral or written English tended to have both academic and social adjustment problems.

Lee et al. (1981) examined literature which found that international students who attended orientation programs had significantly higher knowledge of the university's regulations than those who did not. This insight into international students use of student services relates to their findings that international students who attended an orientation progran had higher English language test scores and higher academic performance (19). Lee et al. concluded that self-evaluated command of English was a substantial predictor of satisfaction in a variety of needs. In order for students to feel satisfied with their stay, a sound preparation in English skills is a must (131). Lee et al. measure that satisfaction in several ways:

Those students who reported a greater command of English skills tended to be more satisfied with the university environment; i.e. measured as a composite of understanding the grading system and course requirements, 
opportunities to discuss course work with faculty

members, getting advice from academic advisors, [eto.]

(Lee et al., 1980, 80).

Researchers have been interested in the link between the level of English proficiency required for international students to fully attend American universities and those students' actual performance once admitted. Greis (1984) discusses the dichotomy between language proficiency and academic competence. He notes that the 1983 TOEFL Manual assumes "that once non-native English speakers have achieved language proficiency they will somehow automatically make a smooth transition to their academic courses" (4). Verts (1994) concurs, adding that "just because a student has acquired an arbitrary level of English competence does not mean that he or she is ready to compete at the university on a level equal to the native speaker" (1). Verts adds that ESL students don't want to hear that they need to do more to prepare for university work besides learn English. But she lists several tasks ESL students in her program need improvement in: rhetorical style, classroom behavior, approach to teachers, and the importance of timelines and deadlines. Personal adjustment and socialization is difficult. She stresses that to admit a student into the university based on TOEFL scores, register him/her for classes, and then abandon that student to the "storms of the campus is nothing less than immoral" (3).

Light, Xu, and Mossop (1987) feel that "academic success may require different levels of language skills at different campuses and 
for different academic majors" (253), but that international students with below-standard TOEFL scores who are nevertheless admitted for other reasons of ten outperform students whose TOEFL scores were in the acceptable range. Compounding this apparent contradiction, Graham (1987) says that universities assume that a certain level of English proficiency is necessary for successful college work, and that they further assume that an ESL professional should know what that level is. But in her research of existing studies, she discovers that the link between English language proficiency and academic success is "murky indeed" (506) and that some researchers say there is no link. She questions whether the TOEFL actually measures communicative competence, since institutions admit only those students who have demonstrated a high level of language competence; this high English proficiency can not be measured against the low English proficiency of students who were refused admittance as a factor influencing academic success. She adds that "one would expect that general intelligence and academic skill . . would have an effect on academic performance" (515-516). Graham thus recommends that admissions offices adapt English proficiency requirements to the number of ESL support services available on a particular campus. This recommendation may reflect on studies such as the present study at Southern Oregon State College if a relationship between number of support services provided for (and used by) ESL students and academic success is established in future research.

Language proficiency studies look most closely at what is asked 
of ESL students before they begin their academic work in contrast to their later success. But what is provided for these students after they have passed academic proficiency standards? In most cases they are treated like American students with the exception of access to a Foreign Student Advisor and invitation into some kind of international club or group. All other student services and resources are provided to a general campus population or other specific groups such as minority or disabled students. Measuring how these resources are perceived and used by international students is the focus of the next chapter. 
CHAPTER III

METHODOLOGY

This chapter will introduce and explain the methodology used in this study, including the population and sample used, how the data was collected, how the instrument was developed including factors of validity, reliability and piloting of the instrument, and how the data is treated.

In the case of the present study, the most appropriate instrument (Agler 1980) was revised partly by reviewing information taken from other sources, especially lee et al. (1981). The results of the revised survey and any conclusions which may be drawn should provide information to the persornel services at Southem Oregon State College which will allow then to better assist international students.

\section{Population and sample}

The population of Southern Oregon State College is comprised of 4515 full-time and part-time students who were enrolled during the Spring quarter of 1996 at Southern Oregon State College. The number of international students enrolled at Southern Oregon State College in 1995 (SOSC Bulletin 1995-96, 2) was 160 , which is $3.6 \%$ of the total number of students on campus. Only those students who have attended Southern Oregon State College for at least one quarter are 
included in this study.

In drawing the sample an attempt was made to reach 30 percent of the international students currently enrolled. This sample size was considered sufficient due to stratified selection which accomplished a representative sample. The 30 percent figure resilted in the need for approximately 53 international students. Since international students are found in higher proportions in the sciences, courses from these departments were chosen for sampling of upper-division courses. Composition and restricted writing courses provided the remainder of the ESL students sampled.

The task of sampling 30 percent of the entire student population at Southern Oregon State College would require that a total of 1500 students be included in the survey. Since the hypothesis being tested is that international students would use student services less than American students, it was not necessary to maintain a ratio of American students sampled to international students equal to that of the college enrollment. For this reason, a nearly 1:2 ratio was used, with a total sample of 95 American students.

Southern Oregon State College is currently considering revising its student services. The Student Services and Counseling Center has, coincidentally, created its own questionnaire for this purpose. In 1994, a questionnaire by an undergraduate student, Mitsuko Tanaka, collected the perceptions of international students on a number of aspects about SOSC, including their perceptions of student services. 
One result was that international students now have drop-in counseling at the student center. The advisor for the guestionnaire, Larry Nollenberger, Director of the Academic Advising program, also indicated that international students desired more information about student services.

This study is a more formal evaluation of how extensively student services are actually used by international students as opposed to American students. The results of the study will be made available to the Dean of Student Affairs and Dr. Nollenberger and have been requested for use in conjunction with the information gathered in the accreditation survey.

It was a concern of the Office of Student Affairs that this study, timed as it coincidentally was with their own, would produce survey fatigue in the students. This concern was addressed carefully by ensuring that the samplings did not overlap.

\section{Data collection}

Survey research has increased in recent years with the questionnaire or interview being the most commonly used methods. The interview technique has the disadvantage of requiring a great amount of time in the collection of data. The disadvantage of the mailed questionnaire is nonresponse and the possibility of bias. According to Withey (1980), "Those who answer questionnaires differ from those who do not. Similarly, those who cannot or will not be interviewed 
are different from those who acquiesce" (1448). In order to maximize returns and obtain a representative sample of respondents, the questionnaire method was used in this study and given to a stratified sample of classes.

Department heads were contacted to gain permission to distribute the questionnaires during class time. It was estimated that eight classes of more than twenty students each would provide a minimum of 100 samples without replication, with a high end of 200 samples. Department heads in English, Engineering, Marketing, and Economics agreed to allow their departments to take part in the questionnaire and provided lists of instructors who taught courses with appropriate enrollments. These heads also assisted in making the initial contact with the instructors. Instructors were given a description of the study and asked to donate fifteen to twenty minutes of class time.

Both lower-division and upper-division courses were chosen for distribution of the questionnaire in order to ensure that a broad range was represented in the sampling. The lower-division courses chosen were among those required for all majors, (two sections of Writing 123 and Speech 125), and the upper-division courses were divided equally among the other four schools or departments for several reasons: to avoid duplication of students as much as possible, to generate a broad range of majors in the sample, to lessen the burden of involvement in any one department, to avoid survey fatigue in students by not sampling courses targeted by 
another concurrent survey at the college, and to increase the chances that international students, who tend to major in certain fields over others, would be included. The actual courses in which questionnaires were distributed were English 101 and 103 (2 sections), Writing 123 (2 sections), Speech 125, History 453, Business 447, Economics 320 and Economics 202. Permission to survey several courses in Engineering and Computer Science was later withdrawn by the Dean of Student Affairs due to a fear of the impact of "survey fatigue" upon an imminent campus-wide survey in which those classes were to take part.

Two courses offered by the English Department, English 101 and 103, were specifically included because they are restricted to fullyadmitted international students, who range in level from freshman to graduate student and include students who have been on campus from one term up to more than one year.

Because of the need for willingness on the part of instructors to participate, along with the specific inclusion of English 101 and 103, the selection of courses is not completely random. However, no specific students were chosen for the sample.

The same person distributed the questionnaire in each participating class to ensure that directions given were clear and consistent and that the sampling procedure was stringently followed. That person (myself) made appointments to explain the questionnaire to each of the instructors who agreed to give up class time.

Three days were set aside to administer the questionnaires. A 
total of ten classrooms were visited over those three days. The completion of the questionnaire was allotted the first or last twenty minutes of class time, as determined by the preference of the instructor. I both passed out and collected the questionnaires myself, and answered student questions as well as gave directions for completion to the students. In the case of Writing 101 and 103, an additional ten minutes was provided for completing the questionnaire. In the case of Writing 123, an additional ten minutes was used to provide information about the focus of the study and the problem being examined to the students, who were being introduced to the idea of primary research.

The number of responses received totalled 148, resulting in a $30 \%$ sample of international students and a $3.4 \%$ sample of students overall at Southem Oregon State College. International student responses comprised $33.5 \%$ of the total responses received.

\section{Instrument development}

An instrument was used which not only assesses the objectives of student services, but also assesses resources available to students outside the classroom. There was no direct relationship intended between the objectives found in Section $I$ and the resources identified in Section II. Fulfilling a specific objective is facilitated by a number of resources.

Section I of the present questionnaire is taken from a study by Agler (1981), revised so that the vocabulary is more accessible to 
international students. Agler's questionnaire in turn largely reflects a modified version of the Survey of Student Personnel Qbjectives developed by McDavis (1974). His survey was based on the Inventory of Student Fersonnel Objectives. McDavis reports that the inventory was evaluated by a panel of student personnel researchers, educators, and practitioners. These "expert" judges selected fifty objectives to be retained from a pool of sixty. The criterion for retaining an objective was "relevance to student services" (6). At least three-fifths of the panel had to agree that an objective was relevant before being retained.

For the purposes of Agler's (1980) study, 22 of McDavis's items in the survey were considered relevant because of their applicability to students. The omitted items from the McDavis survey considered irrelevant reflected services offered to faculty, administrators, and to other non-student members of the university community. Agler also added and subsequently pretested two items considered congruent with the goals and mission statement of the university where she conducted her study: "To provide well defined policies regarding standards and regulations" and "To provide disciplinary procedures which are growth experiences." The University of La Verne (in southern California), where Agler conducted her study, is a parochial school which promotes Christian values; while some of the items in the survey appear to focus more strongly on values than similar studies designed for nonreligious colleges, all of these objectives were taken from the McDavis instrument which was compiled through the input of a panel of 
national experts in the field of student personnel services. Still, an important consideration would be whether objectives concerning personal values are appropriate for inclusion in a questionnaire administered in a public institution. After the pros and cons of including this objective were weighed, it was included in the final form of the questionnaire in order to provide data about whether this was an important issue for international students at a public institution. At Southern Oregon State College, almost half of the students are from Mexico, where religious values generally hold a higher priority in the lives of its populace. Would the lack of association with such values be an important factor in the educational experience of international students? Yet international students may also feel that "developing a system of values" is a very private matter which should not be considered a part of a university education. It is difficult to determine the import of this question, and although the international students who piloted the instrument (all Japanese) expressed no discomfort, on the other hand, there was unfortunately no assurance that their understanding of the term "values" had the same import as that which was intended by a questionnaire originally devised for native speakers. This issue is discussed in further detail in the section on reliability and validity issues.

Agler modified the response codes of "yes," "no," and "don't know" used in the McDavis study. For each of the objectives, two questions were asked regarding the imortance of a given objective as 
perceived by the student, and the degree of effectiveness of a given objective as perceived by the student. The response alternatives which the student used to assess importance included "very important," "important," "of little importance," and "not important." The response alternatives which the student used to assess effectiveness included "very effective," "effective," "Iimited effectiveness," "not effective," "not applicable at your level," and "don't know." This modification allowed the researcher to compare the importance of the objectives with the effectiveriess of those objectives as perceived by the students. The comparison of perceived importance with effectiveness allowed the creation of a "Need Index" which was used in determining the need for each objective and the degree of fulfillment of that need. The present study at Southern Oregon State College also uses the Need Index in comparing the degree of fulfillment of needs of American students and international students as well as the factor of English proficiency.

After her study, Agler recommended that the following objectives be dropped from the survey: "To assist in interpreting student actions to the local community," and "To assist in interpreting student actions to the university community." Due to respondents" confusion over the questions, a lareg number of "don't know" and "not applicable" responses occurred, suggesting that these objectives were either irrelevant or unclear. These objectives therefore were not included in the present study.

Section II, of the Survey of Services for Students 
guestionnaire, also taken from Agler, lists resources for students outside of the classroom and asks the student to select from anone several response categories: "very helpful," "helpful," "of limited help," "not helpful," "not applicable," and "don't know." An opportunity is provided at the end of the survey for respondents to list any of the resources in which they would desire more help. Agler added the categories of "financial aid" and "campus security" to the list of resources in the original McDavis survey. She recommended in the final discussion of her study that students also be given the opportunity to indicate if they are disabled.

An additional section on population characteristics in the questionnaire was designed to provide information in relation to the respondents' age, sex, marital status, full or part time student. status, undergraduate level, length of time at the university, extent of participation in extracurricular activities at the College, and national/international status.

Agler's questionnaire was modified for the study at SOSC in a number of ways. Four employees of Southern Oregon State College recomended revisions. These employees represent the scope of the staff at the college and include a counselor in the Student Resource Center, the Foreign Student Advisor, the Associate Dean of Students, and an instructor who teaches both American and international students.

Two questions from Part I of Agler's study were deleted because they were found not to be relevant at SOSC. The terms "important" 
and "effective" were the source of much discussion which resulted in a change of wording throughout Part I of the questionnaire. Agler's terms were compared to a similar section of the College Outcomes Survey published by the American College Testing Program, which asked students about their use of student services. In some ways, Agler's questionnaire is quite similar to the College Outcomes Survey; however, while the term "important" was retained, the term "well" was used instead of "effective," so that the whole question was worded "How well is this service performed?" instead of "How effectively is this service performed?" This change was adopted in the present study.

The staff reviewing the questionnaire also made recommendations about Part II, Resources for Students Outside of the Classroom. Several categories were deleted from Agler's study as they were services which are not provided at SOSC. Other categories were proposed and ultimately added, including "Women's Center," "Writing Center," "Math Center," and "Disabled Student Advisor." Three categories were combined and reworded as "Academic Resource Center." Three other categories were reworded for clarity.

The guestions on student demographics are almost unchanged from Agler's study, except that colleges and majors which do not exist at Southem Oregon State College were deleted. One of the questions was reworded to ensure that international students would understand the vocabulary. The term "objective" was changed to "goal."

An additional page of questions was provided for international 
students in the present study, asking for country of origin, first language, self-reported TOEFL score and a self-assessment of English proficiency. These last two questions were inspired by Lee et al. (1981), who found a correlation between self-reported English proficiency and satisfaction with needs being met, but found no correlation between needs being met and TOEFL score. There is a full sample of the questionnaire in Appendix A.

\section{Reliability and validity issues}

Would this study be replicable at another institute of higher learning? The instrument would have to be examined for relevance as far as the objectives in Section I being in accordance with the mission statement of the college or university, and as far as the resources listed in Section II being provided at the college or university. With appropriate additions and deletions made in these cases, the study should be replicable as long as there is an international student population present. However, the results of the study might be quite different. This study is not meant to provide data about institutions of higher education in America in general, but only about the population at Southern Oregon State College. The data should not be extrapolated to have importance beyond that institution.

The instrument can be tailored to an individual institution and efforts were made to ensure that it did fit the objectives and resources provided at Southern Oregon State College. The study 
itself is being conducted concurrently with the College Outcomes Survey, which is intended to provide a much broader spectrum of demographic and college-related data but still focuses in part on the use of student services. Administrative personnel have requested the opportunity to compare the results of the data in this study with the data in the College Outcomes Survey. If the results of questions in the College Outcomes Survey which are similar to those in this study concur in both cases, reliability would be suggested.

In discussing the instrument with college personnel at SOSC, vocabulary issues were addressed to ensure that international students would understand objectives in the same way that they were understood by American students. The SOSC personnel panel pointed out problematic words and phrases, and a consensus for alternative language was agreed upon; the students who subsequently piloted the instrument expressed no difficulty in understanding the terms. However, their comprehension was not back-tested; they were not asked to define these terms. Agler's study did not address any issues of reliability or validity, especially in the area of how terms would be understood by individual students. Interestingly, although Agler complained in her study that Law School students at La Verne did not seem to define questions in the same light as undergraduate and graduate students, she did not make recommendations for checks on content validity in her discussion. The present study lacked indepth checks as well. For example, the SOSC panel did not focus on the subjective conception of the term "values," especially as it is 
expressed in one objective, "developing a system of values." Whether this term is understood equally by international and American students was not established, raising a question of content validity. Because the panel did examine the questionnaire and the piloting students did discuss difficulties with vocabulary, the instrument does possess face validity.

\section{Eiloting of the instrument}

For the purpose of this study and its application to Southern Oregon State College, a piloting of the instrument was conducted. The questionnaire was pretested by administering to an undergraduate group of ten students, including 5 international students who agreed to participate as a sign of friendship for a former SOSC instructor. A sample testing was needed in order to provide participating instructors with a time-frame to allot for the administration of the questionnaire. The sample students were asked to take the questionnaire at normal speed in their classroom environment. The sloweat student took 30 minutes to complete the questionnaire. This total included minutes needed to administer directions and answer questions. The sample testing was found to be especially useful since five of the participants were international students. The question of whether or not they would have difficulty with the vocabulary or time allotment to answer their additional page on demographics was answered. On the average, the five international students completed the questionnaire within 18 minutes, while the 
American students took 14 minutes. On the basis of student. questions about the questionnaire, the following changes were made: the terms "commuter," "values," and "not applicable" were briefly explained before administering the questionnaire, and the purpose of the study was described in general terms. The importance of answering every question in some way was stressed.

Treatment of the data

The data were examined in two parts. The first part was student perceptions of objectives of student services, as indicated in Section I of the questionnaire, and the second part was helpfulness of resources outside of the classroom, as indicated in Section II of the questionnaire.

The treatment of the data in many respects closely replicates the method used by Agler (1980). Agler's intent in building the questionnaire was to analyze the categories shown in the following analysis column. A response was desired to determine, for instance, if a particular objective was important or not important. To facilitate students ease in answering the questions, the response options were expanded, as indicated in the chart. To clarify, a student had the option of choosing responses ranging from "Very important," "Important," "Of little importance," and "Not important." The "Very important" and "Important" categories were tallied together under the category "Important," and the "Of little importance" and 
"Not important" categories were subsequently tallied together under the category "Not important." A similar strategy was used for the responses concerning effectiveness and helpfulness.

The data were tabulated yielding a frequency and a percentage distribution. After collapsing the categories, the data from the questionnaire were analyzed to determine the needs of students regarding objectives and to determine the helpfulness of resources. For determining needs, the responses of "importance" and "effectiveness" were examined first, followed by an examination of these two categories together which constituted a need index.

\begin{tabular}{ll}
\hline Categories for Analysis & Categories in Survey \\
\hline Important & $\begin{array}{l}\text { Very Important } \\
\text { Important }\end{array}$ \\
\hline Not Important & $\begin{array}{l}\text { Of Little Importance } \\
\text { Not Important }\end{array}$ \\
\hline Effective & $\begin{array}{l}\text { Very Well } \\
\text { Well }\end{array}$ \\
\hline Not Effective & $\begin{array}{l}\text { Not Very Well } \\
\text { Poorly }\end{array}$ \\
\hline Helpful & $\begin{array}{l}\text { Very Helpful } \\
\text { Helpful }\end{array}$ \\
\hline Not Helpful & $\begin{array}{l}\text { Of Limited Help Hul } \\
\text { Not }\end{array}$ \\
\hline
\end{tabular}


The following hypotheses were tested. In addition, student services objectives were rank ordered according to their importance and effectiveness, thus yielding their relative value.

\section{Importance of objectives}

1. Null Hypothesis: No statistically significant difference exists between American students and international students in the perceived "importance" of the various objectives of student services. Statistical Test: the data from the guestionnaire are nominal; therefore, the Chi-square test was used to determine if there were significant differences between American and international students, with the level of significance equalling 05 .

2. Rank Order of "importance" of objectives: the responses of international students and American students were examined further in order to determine the extent of differences among the objectives. A ranking process was used. The following categories were established for this purpose. 


\author{
objectives \\ Degree of Importance \\ Exceptionally Important \\ $80 \%$ or greater "important" responses \\ Important \\ $50 \%$ through $79.9 \%$ "important" responses \\ Moderately Important \\ 40\% through 49.9\% "important" responses \\ Not Important \\ $40 \%$ or greater "not important" responses
}

In Agler's (1980) utilization of this rating scale; for each objective the highest percentage of responses in a category had to be at least ten points higher than any other response in that category in order to qualify for listing in the table. A simple majority would not have allowed for the more important responses to be included. Since the data were dichotomous, binomial tests were conducted to determine what the level of discrepancy would be between response categories to achieve a statistically significant difference. Agler's analysis indicated that a 10 percent differential would be sufficient when analyzing data from a sample of from 100 to 300 respondents, and a 16 percent differential would be needed for a sample of between 40 and 50 responses. However, Agler applied the 10 percent differential to all her samples for the sake of consistency (55). The 10 percent differential is applied to this 
study as well, since the total number of respondents (148) falls into the range used by Agler.

Agler chose a minimum of 40 percent of "important" responses as required for inclusion in the listing; less than 40 percent was judged to be an insufficient percentage for listing; this number represented a reasonable degree of support, allowing one dominant response to emerge for a particular objective, whereas 30 percent would allow more than one response to emerge and 50 percent would allow too few to be recorded.

3. An analysis of the demographic characteristics was made regarding "importance." Since the demographic data relating to these characteristics were frequently sub-divided into several categories (for example, the length of time the students had been attending the college), the number in each category was often too small to be measured through the Chi square statistical analysis; therefore, the following two-step measure established by Agler was followed: A minimum of 40 percent in any response category was essential; in addition, the 40 percent or above measure had to be at least 10 percent higher than the next largest category.

\section{Effectiveness of objectives}

1. Null Hypothesis: No statistically significant differences exist between American and international students in the perceived "effectiveness" of the various objectives of student services. 
Statistical Test: The data from the questionnaire are nominal; therefore, the Chi-square test was used to determine if there were significant differences between American and international students, with the level of significance equalling .05.

2. Rank Order of "effectiveness" of objectives: American and international students as groups were examined further in order to determine the extent of differences among the objectives. A ranking process was used. The following categories were established for this purpose.

\author{
Objective \\ Degree of Effectiveness \\ Exceptionaliy Effective \\ $80 \%$ or greater "effective" responses \\ Effective \\ $50 \%$ through $79.9 \%$ "effective" responses \\ Moderately Effective \\ $40 \%$ through $49.9 \%$ "effective" responses \\ Ineffective \\ $40 \%$ or greater "not effective" responses \\ Not Applicable \\ $40 \%$ or greater "not applicable" responses \\ Don't Know \\ $40 \%$ or greater "don't know" responses
}


3. An analysis of the demographic characteristios was made regarding "effectiveness." Since the demographic data relating to these characteristics were again too small to be measured through the Chi square statistical analysis, Agler's two-step measure was followed: a minimum of $40 \%$ in any response category was essential. In addition, the 40 percent or above measure had to be at least 10 percent higher than the next largest category.

Need of students regarding objectives

To determine "need," an index was established based on Agler.s methods, through a combination of "importance" and "effectiveness" ratings for objectives. Based on this information, a rank order was established yielding the extent of need from greatest to least.

1. Need Index:

a. If an objective was perceived as being "important" and "effective" by a respondent, the need was considered fulfilled.

b. If an objective was perceived as "not important" but "effective," the objective was considered overemphasized.

c. If an objective was perceived as "important" but "not effective," this was considered as an unfulfilled need.

d. If an objective was perceived as "not important" 
and "not effective," there was no nood for meeting the objective.

2. Rank Order of "needs" of students: American and international students as groups were examined further in order to determine the extent of need. A ranking process was used. The following categories were established by Agler for this purpose and are used in this study.

\author{
Need \\ Degree of Fulfillment \\ Exceptionally Fulfilled \\ $80 \%$ or greater "need fulfilled" \\ Eulfilled \\ $50 \%$ through $79.9 \%$ "need fulfilled" \\ Moderately Fulfilled \\ $40 \%$ through $49.9 \%$ "need fulfilled" \\ Unfulfilled \\ $40 \%$ or greater "need unfulfilled" \\ Not Applicable \\ $40 \%$ or greater "rot applicable" \\ Don't Know \\ $40 \%$ or greater "don't know"
}

3. An analysis of the demographic characteristics was made regarding the index of need since the data relating to these 
characteristics were too small to be measured through the Chi square.

\section{Helpfulness of resources}

1. Null Hypothesis: No statistically significant differences exist between American and international students in the perceived "helpfulness" of the various resources available to students. Statistical Test: The data from the questionnaire are nominal; therefore, the Chi square test was used to determine if there were significant differences between American and international students, with the level of significance equally .05.

2. Rank Order of "helpfulness" of resources. American and international students were each examined further in order to determine the extent of differences among the resources. A ranking process was used. The following categories were established for this purpose. 


\author{
Resources \\ Degree of Helpfulness \\ Exceptionally Helpful \\ $80 \%$ or greater "helpful" responses \\ Helpful \\ 50\% through 79.9 "helpful" responses \\ Moderately Helpful \\ 40\% through $49.9 \%$ "helpful" responses \\ Not Helpful \\ $40 \%$ or greater "not helpful" responses \\ Not Applicable \\ $40 \%$ or greater "not applicable" responses \\ Don't know \\ $40 \%$ or greater "don't know" responses
}

3. An analysis of the demographic characteristics was made regarding "helpfulness" of resources. Since the data relating to these characteristics were too small to be measured through the Chi square statistical analysis, the following two-step measure was established as used by Agler: a minimum of 40 percent in any response category was essential; in addition, the 40 percent or above measure had to be at least 10 percent higher than the next largest category.

An additional analysis of several of the demographic categories was based on the total of "don't know" responses to measure lack of 
knowledge. Lack of knowledge was determined by tallying "don't know" scores in Section II for each questionnaire, then dividing the total from all questionnaires in each demographic category by the number of students in the category to create an average of number of "don't know" responses for students in each demographic group.

\section{English language proficiency factor}

In order to determine whether proficiency in English affected the use of student services by international students, international respondents were asked to both report their last TOEFL score if they had taken the test and to give a self-evaluation of their English language ability in eight areas of academic proficiency along a range of 1 to 4,4 being the highest. These self-reported scores were added to create a raw number for each international respondent, which was then compared to the need index for each student. The TOEFL scores were also compared to the need index, with the hypothesis that there would be a correlation between fulfilled needs of student services and English language proficiency. To create the correlation, the self-reported scores were divided into 5 ranges, from $32-30,29-27,26-24,23-21$, and 20 and under. The ratio of fulfilled needs as determined by the Need index was compared to the unmet needs and "don't know" responses. This same formula was applied to a range of the TOEFL scores, which were divided into 3 ranges as a result of the scores provided: 400-500, 501-550, and 
over 551. The need index scores of students who did not take the TOEFL were not considered. 


\section{CHAPTER IV}

\section{RESULTS}

This chapter presents an analysis of the data. Section $I$ is a description of the sample returns, including examination of population characteristics of the respondents. The importance and effectiveness of the twenty-one objectives of student services are examined by noting statistically significant differences between international and American students, followed by an examination of the objectives for international students as a group and for American students as a group, noting specific student characteristics where relevant.

The needs of students as they relate to the objectives were identified by examining the relationship of the importance and effectiveness ratings. The needs of American students as a group and of international students as a group are assessed, followed by a comparative needs assessment between American and international students, noting specific student characteristics where relevant.

In the second section the findings in the area of helpfulness of resources is presented. American students are compared to international students. Demographic characteristics are examined to discover if lack of knowledge of student resources is related to specific student groups.

In the third section intemational students' English language 
proficiency as measured by both TOEFL scores and by self-reported ability is compared to fulfilled needs to determine if there is a relationship.

Section IV presents a summary of the findings.

\section{Sample returns}

The results are tabulated from a total of 148 responses from American and international students, resulting in a 3.5 percent sample of the students, both full and part time. The responses number 53 from the international students and 95 from American students.

Table XIII in Appendix $\mathrm{C}$ provides the percentage and number in each of the subgroups of population characteristics. Forty three percent of the respondents were female and 57 percent were male, while the college population is 46 percent male and 54 percent female. Fifty seven percent of the respondents were between 17 and 23 years old compared to 64 percent of the population of the college.

\section{Section I}

\section{Importance of Objectives}

Statistically significant differences using the Chi-square are presented, followed by rank order interpretations, and an analysis of differences grouped according to population characteristics. 
Differences between international and American students

Table I indicates that significant differences occur between the two groups in responses to 3 of the objectives regarding importance, thereby rejecting the null hypothesis that there would be no significant differences in the pattern of responses when international students were compared to American students. Since all the objectives for the two groups were considered important by the respondents, differences appear to be in the degree of importance, with international students finding the objectives slightly more important than American students. Exceptions and additional findings are noted.

Response differences occurred between the two groups for objectives in the following areas: understanding selves as individuals and developing a system of values. Both responses were positive, with international students reflecting the higher rankings.

A response difference occurred between the two groups in the objective of developing leadership and organizational skills, with American students reflecting the higher positive response.

Rank order interpretations for each group and a comparison between the two groups

Both the American group and the international group are examined further for differences based on the rank order described in Chapter III.

Tables II and III give these perceptions of importance showing 
SIGNIFICANT DIFFERENCES OF PERCEPTIONS OF IMFORTANCE AND EFFECTIVENESS OF OBJECTIVES BY RESEONDENT GROUPS

$\mathrm{N}=$ International 53; American 95

Groups $=$

I (International)

A (American)

\begin{tabular}{|c|c|c|c|c|c|c|c|c|c|c|c|c|c|c|c|}
\hline \multicolumn{2}{|c|}{ Important } & \multicolumn{2}{|c|}{$\begin{array}{c}\text { Not } \\
\text { Important }\end{array}$} & \multicolumn{2}{|c|}{ Missing } & \multicolumn{2}{|c|}{ Effective } & \multicolumn{2}{|c|}{$\begin{array}{c}\text { Not } \\
\text { Effective }\end{array}$} & \multicolumn{2}{|c|}{$\begin{array}{c}\text { Not } \\
\text { Applicable }\end{array}$} & \multicolumn{2}{|c|}{$\begin{array}{l}\text { Don } t \\
\text { Know }\end{array}$} & \multicolumn{2}{|c|}{ Missing } \\
\hline$\%$ & $\mathrm{~N}$ & $\%$ & $N$ & $\%$ & $\mathrm{~N}$ & $\%$ & $N$ & $\%$ & $N$ & $\%$ & $\mathrm{~N}$ & $\%$ & $\mathrm{~N}$ & $\%$ & $\mathrm{~N}$ \\
\hline
\end{tabular}

1. SOSC provides opportunities which help students understand themselves as individuals.

$\begin{array}{lllllllllllll}\text { I. } & 85(46) & 15(7) & 0 & 0 & 43(23) & 32(17) & 2 & (1) & 19(10) & 4 & (2) \\ \text { A. } & 68(65) & 32(30) & 0 & 0 & 39(37) & 17(16) & 1 & (1) & 42(40) & 1 & (1)\end{array}$

2. SOSC provides opportunities which help students develop decision-making skills.

I. $92(49) \quad 8 \quad(4) \quad 0 \quad 0 \quad 45(24) \quad 28(15) \quad 2 \quad(1) \quad 21$ (11) 4 (2)

A. $86(82) 11(10) 3(3) \quad 46(44) \quad 24(22)$ o 0 (3) $24(23) 6$ (6)

3. SOSC provides opportunities which help students develop a system of values.

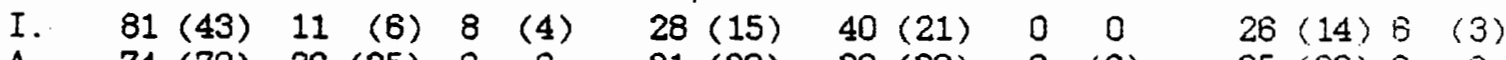

A. $74(70) \quad 26(25) \quad 0 \quad 0 \quad 21(20) \quad 38(36) \quad 6 \quad(6) \quad 35$ (33)

4. SOSC provides opportunities for students to be aware of the values held by others.

\begin{tabular}{lllllllllllllll} 
I. & $85(45)$ & 9 & $(5)$ & 6 & $(3)$ & $21(11)$ & $47(25)$ & 0 & 0 & $27(14)$ & 5 & $(3)$ \\
A. & $86(91)$ & 9 & $(9)$ & 0 & 0 & $47(45)$ & $26(25)$ & 1 & $(1)$ & $26(24)$ & 0 & 0 \\
\hline
\end{tabular}

5. SOSC provides opportunities which help students leam to relate to one another.

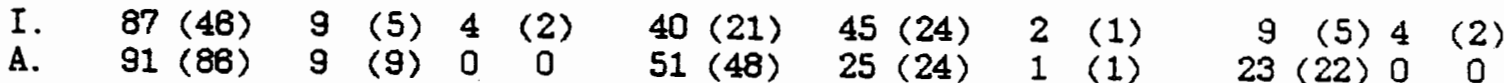


$\begin{array}{cccc}\text { Not } & \text { Not } & \text { Not } & \text { Don't } \\ \text { Important Important Missing } & \text { Effective Effective Applicable } & \text { Know Missing }\end{array}$

$\begin{array}{lllllllllllllllll}\% & \mathrm{~N} & \% & \mathrm{~N} & \% & \mathrm{~N} & \% & \mathrm{~N} & \% & \mathrm{~N} & \% & \mathrm{~N} & \% & \mathrm{~N} & \% & \mathrm{~N}\end{array}$

6. SOSC provides services which help students to develop their educational careers and goals.

$\begin{array}{rrrrrrrrrrrrrr}\text { I. } & 94(50) & 2 & (1) & 4 & (2) & 62(33) & 21(11) & 0 & (0) & 13 & (7) & 6 & (3) \\ \text { A. } & 100(95) & 0 & (0) & 0 & 0 & 64(61) & 23(22) & 1 & (1) & 11(10) & 1 & (1)\end{array}$

7. SOSC provides opportunities for students to develop leadership and organizational skills.

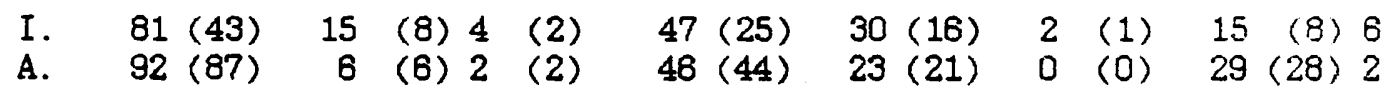

8. SOSC provides opportunities for students to apply their leadership and organizational skills.
I. $83(44)$
11 (6) 6 (3)
$40(21)$
$32(17)$
0 (0) 17 (B) 11 (E)
A. $84(87)$
$13(13)$
38 (36) $23(22)$
4 (4) 35 (33) $\quad 0(0)$

9. SOSC provides opportunities for students to participate on decision-making committees.
I. $\quad 74(39)$
21 (11) 5 (3)
$42(22)$
$19(10)$
4 (2) $30(16) \quad 6(3)$
A. $81(78)$
19 (18) 0
45 (43) $21(20)$
1 (1) $33(31)$
$0(0)$

10. SOSC provides a variety of social, cultural, and recreational activities for students.
I. $81(43) \quad 15$
(8) 4 (2)
66 (35)
$21(11)$
$0 \quad(0)$
7 (4) 8 (3)
A. $91(86)$
(8) 1 (1)
$72(68)$
$12(12)$
(1) $13(12)$
$2(2)$

11. SOSC provides opportunities for students to receive individual help if they noed it.
I. $\quad 91(48)$
4 (2) 5 (3)
58 (31)
28 (15)
2 (1)
6 (3) 6 (3)
A. $95(89)$
(5) 0
72 (88) 19 (18)
0 (0)
9 (9) $0(0)$ 
TABLE I (cont.)

\begin{tabular}{|c|c|c|c|c|c|c|c|c|c|c|c|c|c|c|c|}
\hline \multicolumn{2}{|c|}{ Important } & \multicolumn{2}{|c|}{$\begin{array}{c}\text { Not } \\
\text { Important }\end{array}$} & \multicolumn{2}{|c|}{ Missing } & \multicolumn{2}{|c|}{ Effective } & \multicolumn{2}{|c|}{$\begin{array}{c}\text { Not } \\
\text { Effective }\end{array}$} & \multicolumn{2}{|c|}{$\begin{array}{c}\text { Not } \\
\text { Applicable }\end{array}$} & \multicolumn{2}{|c|}{$\begin{array}{l}\text { Don't } \\
\text { Know }\end{array}$} & \multicolumn{2}{|c|}{ Missing } \\
\hline$\%$ & $\mathbf{N}$ & $\%$ & $\mathrm{~N}$ & $\%$ & $\mathbb{N}$ & $\%$ & $\mathrm{~N}$ & $\%$ & $\mathrm{~N}$ & $\%$ & $\mathrm{~N}$ & $\%$ & $\mathbb{N}$ & $\%$ & $N$ \\
\hline
\end{tabular}

12. SOSC provides advice for student organizations.

$\begin{array}{lllllllllll}\text { I. } & 72(38) & 26(14) & 2 & (1) & 23(12) & 34(18) & 2 & (1) & 37(20) & 4(2) \\ \text { A. } & 66(63) & 34(33) & 0 & 0 & 28(27) & 12(11) & 3 & (3) & 55(52) & 2(2)\end{array}$

13. SOSC helps to develop a campus a tmosphere which adds to the intellectual growth of students.

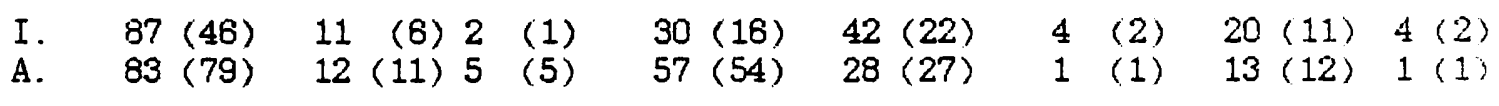

14. SOSC helps to develop a campus atmosphere which adds to the personal growth of students.

I. $87(46) \quad 11$ (6) 2 (1) 47 (25) 28 (15) 2 (1) 15 (B) 8 (4)

A. $84(80) \quad 13(13) 2$ (2) $54(51) \quad 28(27) \quad 4 \quad(4) \quad 14(13) \quad 0$ (0)

15. SOSC provides counseling for students with personal concerns.

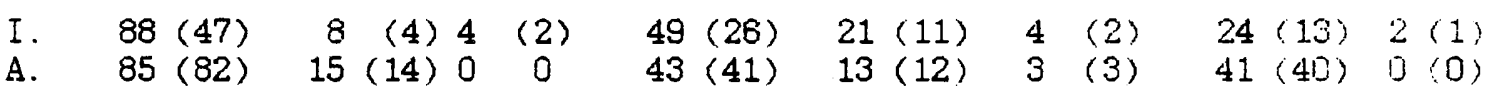

A. $85(82) \quad 15(14) 0 \quad 0 \quad 43(41) \quad 13(12) \quad 3(3) \quad 41(40) \quad 0(0)$

16. SOSC supports awareness of the individual

needs of students.

$\begin{array}{llrlllllllll}\text { I. } & 90(48) & 8 & (4) & 2 & (1) & 36(19) & 36(19) & 4 & (2) & 20(11) & 4(2) \\ \text { A. } & 84(80) & 15(14) & 1 & (1) & 32(30) & 32(30) & 2 & (2) & 33(34) & 1\end{array}$

17. SOSC orients new students to the campus to make them feel like they are a part of the college.

I. $85(45) \quad 15$ (8) $0 \quad 0 \quad 57(30) \quad 34(18) \quad 2 \quad(1) \quad 7 \quad$ (4) $0(1)$

A. $88(82) \quad 12(11) 0 \quad 0 \quad 35$ (34) 41 (39) 3 (3) 21 (19) 0 (0)


TABLE I (cont.)

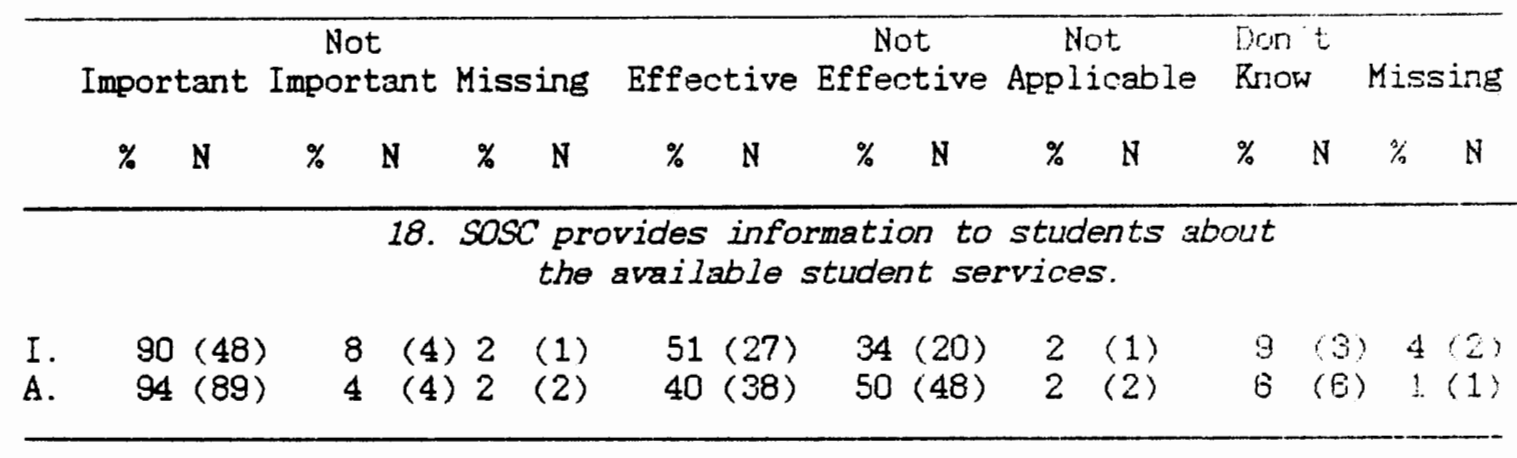

19. SOSC encourages students to use the availabie student services.

$\begin{array}{llllllllllll}\text { I. } & 85(45) & 13(7) & 2 & (1) & 51(27) & 34(18) & 4 & (2) & 9(5) & 2(1) \\ \text { A. } & 86(82) & 13(12) & 1 & (1) & 48(46) & 40(38) & 1 & (1) & 11(10) & 0 & (0)\end{array}$

\begin{tabular}{|c|c|c|c|c|c|c|c|c|}
\hline \multirow[b]{2}{*}{$\begin{array}{l}75(40) \\
89(84)\end{array}$} & \multicolumn{8}{|c|}{$\begin{array}{l}\text { 20. SOSC clearly defines the policies and rules of } \\
\text { the college. }\end{array}$} \\
\hline & $\begin{array}{l}19(10) 6 \\
11(10) 0\end{array}$ & $\begin{array}{c}(3) \\
0\end{array}$ & $\begin{array}{l}43(23) \\
56(53)\end{array}$ & $\begin{array}{l}26(14) \\
33(31)\end{array}$ & $\begin{array}{l}0 \\
0\end{array}$ & $\begin{array}{l}(0) \\
(0)\end{array}$ & $\begin{array}{l}25(13) \\
10(10)\end{array}$ & $\begin{array}{l}5(3) \\
1(1)\end{array}$ \\
\hline
\end{tabular}

21. SOSC provides disciplinary actions which help students to grow.

I. $79(42) \quad 21(11) 0 \quad 0 \quad 32(17) \quad 36(19) \quad 2 \quad(1) \quad 26(14) \quad 4$ (2)

A. $75(71) \quad 25(24) 0 \quad 0 \quad 26(25) \quad 33(31) \quad 1 \quad(1) \quad 39(37) \quad 1$ (1)

Null hypothesis is rejected at .05 level.

Computations are on "Importance" and "Effectiveness" separately. Missing data are not in the Chi-square computation. 
that 17 of the objectives were rated as "exceptionally important" and 4 were rated "important" by the international students. The American respondents also found 17 objectives "exceptionally important" and 4 objectives "important." A few objectives should be singled out for comparison. Both

the international students and the American students identified "developing educational and career objectives" as the most important objective and "advice for student organizations," though seen as important, as the least important of the objectives. "Giving individual help if needed" was also found to be high on the list of exceptionally important objectives for both groups, and "disciplinary procedures which are growth experiences" was found to be low on the list of important objectives for both groups.

\section{Demographic characteristics}

A review of all variables within the demographic characteristics showed no important differences for "importance" of objectives according to age, sex, full or part time student, class standing, length of time at the college, or extent of participation in extracurricular activities.

\section{Effectiveness of Objectives}

Significant differences using the Chi-square formula are presented, followed by rank order interpretations and an analysis of 
differences grouped acoording to population characteristics.

Differences between American and international students

Table I (p. 49-52) indicated the simificant differences regarding the effectiveness of objectives for the categories of "effective," "not effective," "not applicable," and "don't know." Significant differences occurred for 11 objectives. When analyzed individually, the American and international students reflected further differences.

1. Differences were significant between the two groups in response to 11 of the objectives. In 3 of those objectives, American students responded most often in the "effective" category and international students responded most often in the "ineffective" category. These included the following objectives: awareness of the values held by others, learning to relate to one another, and applying leadership and organizational skills.

2. Responses were found to be significantly different between Americans and international students for 2 objectives where international students responded most often in the "effective" category and American students' largest response category was "ineffective." These objectives were orienting new students to the campus and the availability of student services.

3. Responses for 4 of the objectives showed significant differences in the "don't know" category for one or both groups.For 
INTERNATIONAL STUDENT PERCEPTIONS OF IMEORTANCE OF OBJECTIVES BY RANK ORDER

Objective

To provide help to students in:

\section{Exceptionally Important}

6. Developing educational and career goals 94

2. Developing decision-making skills 92

11. Providing individual help if needed 91

16. Awareness of individual needs of others 90

18. Providing information about student services 90

15. Counseling for personal concerns 88

13. Campus climate conducive to intellectual growth 87

14. Campus climate conducive to personal growth 87

5. Relating to one another 87

1. Understanding selves as individuals 85

4. Awareness of values held by others 85

17. Orienting new students to campus 85

19. Encouragement to use available student services 85

8. Applying leadership and organizational skills 83

3. Developing a system of values 81

7. Developing leadership and organizational skills 81

10. A balance of social, cultural \& recreation activities 81

Important

21. Disciplinary actions which are growth experiences 79

20. Defining the policies and rules of the college 75

9. Participating on decision-making committees 74

12. Advice for student organizations 72

Moderately Important

None

Not Important

None 
To provide help to students in:

\section{Exceptionally Important}

6. developing educational and career objectives

11. providing individual help if needed

18. providing information about student services

7. developing leadership and organizational skills 92

5. relating to one another

10. a balance of social, cultural \& recreational activities 91

20. defining the policies and rules of the college 89

17. orienting new students to the campus 88

8. applying leadership and organizational skills 87

19. encouragement to use available student services 86

4. awareness of values held by others 86

2. developing decision-making skills 86

15. counseling for personal concerns 8.5

16. awareness of the individual needs of others 84

14. campus climate conducive to personal growth 84

13. campus climate conducive to intellectual growth 83

9. participating on decision-making committees 81

\section{Important}

21. disciplinary actions which are growth experiences 75

3. developing a system of values 74

1. understanding selves as individuals 68

12. advice for student organizations 66

Moderately Important

None

Not Important

None 
the objective of awareness of the values held by others, the Americans' largest response category was "don 't know" and the international students' largest response category was "ineffective." For the objective of the college providing advice for student organizations, both the Americans and the international students had highest responses in the "don't know" category, with the Americans answering at a higher percentage. American students responded to theobjective of a campus atmosphere conducive to the intellectual growth of students with the highest response category being "effective," while international students responded most highly in the "don " $t$ know" category. The final objective, disciplinary actions which are growth experiences, was responded to most highly by international students in the "ineffective" category and by American students in the "don't know" category. As the questionnaire did not supply a category aimed at allowing international students to signify that they did not understand the terms, "don "t know" could conceivably be taken as "don "t understand" in cases such as the two objectives discussed above, where fairly sophisticated vocabulary is used. If this were the case, the significance of the difference in responses would have to be examined in that light.

4. Responses to two of the objectives were found to be significantly different between the two groups although both responded most often in the "effective" category. These were the objective of providing counseling for personal concerns, with the international students at a significantly higher percentage, and the 
objective of clearly defined policies and rules, with Americans finding it to be more effective than international students.

Rank order interpretations for American and international students

American and international students are examined further for differences based on the rank order of percentages as described in Chapter III. Tables IV and V give these rank ordered perceptions of effectiveness.

\section{International students}

Table IV lists the international student responses, indicating 9 objectives which were listed in the "effective" category: developing educational and career goals; developing leadership and organizational skills; a balance of social, cultural, and recreational activities; availability of individual help; a campus atmosphere conducive to the personal growth of students; pourseling for students with personal concerns; orientation of new students; information about the availability of student services, and encouragement to use the available student services. Four objectives were found to be moderately effective, including understanding selves as individuals, developing decision-making skills, participating on decision-making committees, and clearly defining the policies and rules of the college.

The three objectives found to be ineffective were developing a system of values, awareness of the values held by others, and a 
campus atmosphere conducive to the intellectual growth of students.

The following objectives were not listed, as the responses were similar between "effective" and "not effective": relating to one another and applying leadership and organizational skills.

\section{American students}

American student responses indicated the 7 following objectives were seen as "effective," according to rank order in Table V: a. balance of social, cultural, and recreational activities; availability of individual help; developing educational and career goals; a campus conducive to intellectual growth; a campus conducive to personal growth; clearly defined college policies and rules, and relating to one another. The 4 "moderately effective" objectives were developing decision-making skills, awareness of the values held by others, developing leadership and organizational skills, and participation on decision-making committees.

The objective of providing information about the available student services was found to be "ineffective."

Two objectives were not listed as the responses between "effective" and "ineffective" were similar. These were orienting new students to the campus and encouragement to use the available student services. Two other objectives were not listed as the number of responses for "effective" and "don't know" were too similar to delineate a tendency. These were understanding selves as individuals and counseling for students with personal concerns. 
To provide help to students in:

\section{Exceptionally Effective}

\section{None}

\section{Effective}

10. A balance of social, cultural, and recreation activities 70

6. Developing educational and career goals 65

11. Providing individual help if needed 62

17. Orientation of new students to the campus 57

18. Information about available student services 53

19. Encouragement to use available student services 52

14. Campus climate conducive to personal growth 51

15. Counseling for personal concerns 50

7. Developing leadership and organizational skills 50

\section{Moderately Effective}

2. Developing decision-making skills 47

20. Clearly defining the policies and rules of the college 46

1. Understanding selves as individuals 45

9. Participating on decision-making committees 44

\section{Ineffective}

4. Awareness of the values held by others 50

13. Campus atmosphere conducive to intellectual growth 43

3. Developing a system of values 42

Not Applicable

None

Don't Know

None 
To provide help to students in:

Exceptionally Effective

None

\section{Effective}

10. A balance of social, cultural, \& recreation activities

11. Providing individual help if needed

6. Developing educational and career goals

13. Campus climate conducive to intellectual growth

20. Clearly defining the college policies and rules

14. Campus climate conducive to personal growth

5. Relating to one another

\section{Moderately Effective}

2. Developing decision-making skills

4. Awareness of the values held by others

7. Developing leadership and organizational skills

9. Participating on decision-making comnittees

\section{Ineffective}

18. Providing information about student services

Not Applicable

None

Don't Know

12. Advice for student organizations 
Comparison of the two groups

In a comparison of the American students and the international students, effectiveness ratings outnumbered ineffective ratings for both, with international students showing more ineffective ratings. Neither group had ratings in the highest category, "exceptionally effective." The objective of providing a balance of social, cultural, and recreational activities was seen as the most effectively implemented of all twenty-one objectives for both international and American students. The objectives of "helping students to develop their educational and career goals" and "providing opportunities for students to receive individual help if they need it" were each found to be the second or third most effective goal for both American and international students.

The objective "to develop a campus atmosphere which adds to the intellectual growth of students" was found to be the fourth most effective objective for Americans, but one of the three "ineffective" objectives for international students. The objective found to be most ineffective for international students was "awareness of the values held by others." This objective was, on the other hand, found to be effective by American students. It is important to consider for each objective whether language comprehension considerations are a factor in the perception of international students. Cultural differences regarding the connotation of the idea of values may also contribute to this response by international students. 
Demosraphic characteristics

A review of all variables within the demographic

characteristics showed no important differences for "effectiveness" of objectives according to age, sex, full or part time student, class standing, length of time at the college, or extent of participation in extracurricular activities.

\section{Needs of Students}

This section is based on the combined perceptions of importance and effectiveness of objectives, which results in the "index of need" described in Chapter III. The categories within the index are "need fulfilled," "objective overemphasized," "need unfulfilled," "no need," "don't know," and "not applicable."

In order to examine further the data for extent of need, a rank order of objectives was established for American students and for international students. Tables VI and VII contain the rank order of needs for the two groups.

\section{International students}

As indicated in Table VI, international student needs appear to have been met in seven of the objectives, which were (Iisted in order of highest percentage first) developing educational and career goals, individual help available if needed, a balance of social, cultural \& recreation activities, participation on decision-making comittees, 
orientation of new students, developing leadership and organizational skills, and a campus atmosphere conducive to personal growth. Two more objectives were considered to be "moderately fulfilled": clearly defined college policies and rules and developing decision-making skills. The following two objectives were not listed, as the responses were similar for "need fulfilled" and "need unfulfilled": applying leadership and organizational skills and information provided about the available student services.

International students found the following six needs to be unfulfilled: awareness of the values held by others, developing a system of values, relating to one another, disciplinary actions which are growth experiences, a campus atmosphere conducive to intellectual growth, and advice provided for student organizations.

\section{American students}

According to Table VII, American student needs were met for six of the objectives, which were: (1isted in order of highest percentage first) individual help available if needed; a balance of social, cultural, \& recreation activities; developing educational and career goals; a campus conducive to intellectual Erowth, clearly defined college policies and rules, and developing decision-making skills. The need for five objectives was moderately met. These include a campus conducive to personal growth, developing leadership and organizational skills, relating to one another, awareness of the values of others, and encouragement to use student services. 
To provide help to students in:

\section{Need Exceptionally Eulfilled}

None

Need Eultidled

6. Developing educational and career goals

11. Eroviding individual help if needed

10. A balance of social, cultural \& recreation activities

9. Participating on decision-making committees

17. Orientation of new students

7. Developing leadership and organizational skills

14. Campus climate conducive to personal growth

\section{Need Moderately Fulfilled}

20. Clearly defining college policies and rules

2. Developing decision-making skills

Need Unfulfilled

4. Awareness of the values held by others

3. Developing a system of values

5. Relating to one another

21. Disciplinary actions which are growth experiences

13. Campus climate conducive to intellectual growth

12. Providing advice for student organizations

Not Applicable

None

Don't Know

None 
To provide help to students in:

Need Exceptionally Fulfilled

None

\section{Need Eulfilled}

11. Providing individual help if needed

10. A balance of social, cultural, \& recreation activities 67

6 . Developing educational and career goals 86

13. Campus climate conducive to intellectual growth 52

20. Clearly defining college policies and rules 52

2. Developing decision-making skills 51

\section{Need Moderately Eulfilled}

14. Campus climate conducive to personal growth 49

7. Developing leadership and organizational skills 47

5. Relating to one another 47

4. Awareness of the values of others 40

19. Encouragement to use student services

\section{Need Unfulfilled}

18. Providing information about student services

Not Applicable

Nore

$$
\text { Don't Know }
$$

12. Advice for student organizations 59

1. Understanding selves as individuals 45

21. Disciplinary actions which are growth experiences 40 
American students identified one objective for which the need was unfulfilled: information provided about student services.

American students also responded at higher than a 40 percent level in the "don't know" category for three objectives: advice for student organizations, understand selves as individuals, and disciplinary actions which are growth experiences.

One objective was not listed as the responses were almost equally divided between the "met" and "unmet" responses: counseling provided for students with personal concerns.

\section{Comparison of American and international students regarding need}

For international students, needs were "fulfilled" in eightareas, and "moderately fulfilled" in two areas. For American students needs were "fulfilled" in six areas, and "moderately fulfilled" in five areas. Among these areas, the three objectives of developing educational and career goals, a balance of social, cultural and recreational activities, and individual help available if needed were ranked highest (listed in varying order) for both groups.

Although American students identified only one "unfulfilled" objective, international students identified six, three of which were identified as "fulfilled" or "moderately fulfilled" for Americans: awareness of the values held by others, relating to one another, and a campus atmosphere which is conducive to intellectual growth.

Two objectives which international students identified as 
"unfulfilled" fell into the rankings of "don't know" for Anerican students: advice provided for student organizations and disciplinary actions which are growth experiences.

\section{Section II \\ Helpfulness of Resources}

Significant findings using the Chi square statistic are presented, followed by rank order interpretations and an analysis of responses according to demographic characteristics.

\section{Differences between American and international students}

Table VIII indicated that significant differences occurred in responses of 5 of the twenty resources when the two groups are compared, thereby rejecting the null hypothesis that there would be no significant differences in the responses of American students and international students. The differences noted in "helpfulness" are in the categories of residence hall staff, health center and staff, writing center, financial aid, and foreign student advisor.

Rank order interpretations for American and international students and a comparison of both

No resources were found to be "exceptionally helpful" by either the American group or the international group. American students found three resources to be helpful: other student friends, 
TABLE VIII

SIGNIFICANT DIFFERENCES BETWEEN AMERICAN AND

INTERNATIONAL STJUENTS OE PERCEPTIONS OE

HELPFULNESS OF AVAILABLE RESOURCES

$\mathrm{N}=$ American 95; International 53

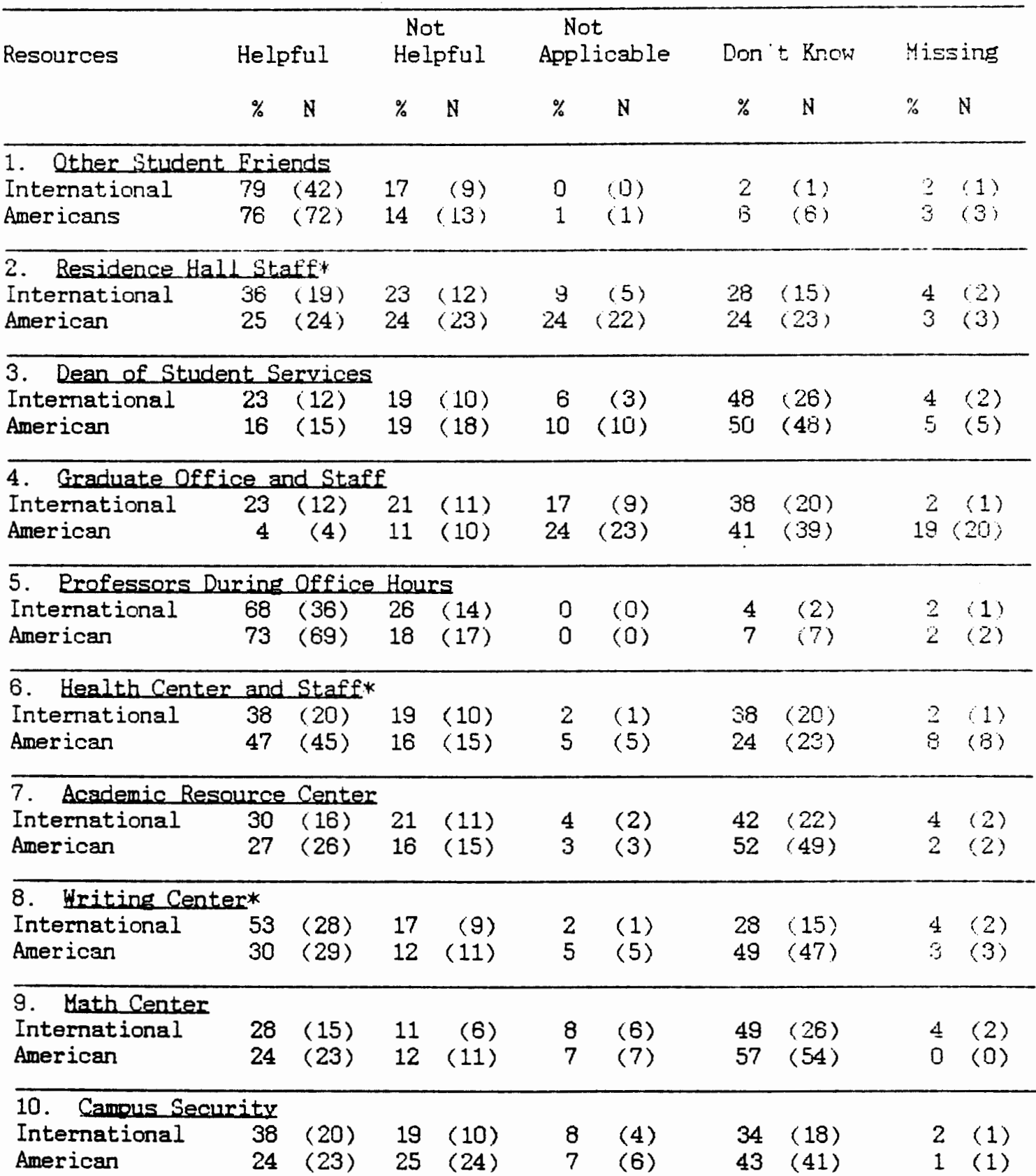


TABLE VIII (cont.)

\begin{tabular}{|c|c|c|c|c|c|c|c|c|c|c|}
\hline \multirow[t]{2}{*}{ Resources } & \multicolumn{2}{|c|}{ Helpful } & \multicolumn{2}{|c|}{$\begin{array}{l}\text { Not } \\
\text { Helpful }\end{array}$} & \multicolumn{2}{|c|}{$\begin{array}{l}\text { Not } \\
\text { Applicable }\end{array}$} & \multicolumn{2}{|c|}{ Don't know } & \multicolumn{2}{|c|}{ Missing } \\
\hline & $\%$ & $N$ & $\%$ & $\mathrm{~N}$ & $\%$ & $\mathrm{~N}$ & $\%$ & $\mathrm{~N}$ & $\%$ & $\mathrm{~N}$ \\
\hline $\begin{array}{l}\text { 11. Program An } \\
\text { International } \\
\text { American }\end{array}$ & $\begin{array}{l}\text { sor } \\
36 \\
35\end{array}$ & $\begin{array}{l}(19) \\
(33)\end{array}$ & $\begin{array}{l}32 \\
13\end{array}$ & $\begin{array}{l}(17) \\
(12)\end{array}$ & $\begin{array}{l}2 \\
3\end{array}$ & $\begin{array}{l}(1) \\
(3)\end{array}$ & $\begin{array}{l}28 \\
46\end{array}$ & $\begin{array}{l}(15) \\
(44)\end{array}$ & $\begin{array}{l}2 \\
3\end{array}$ & $\begin{array}{l}(1) \\
(3)\end{array}$ \\
\hline $\begin{array}{l}\text { 12. Einancial } \\
\text { International } \\
\text { American }\end{array}$ & $\begin{array}{c}d * \\
28 \\
42\end{array}$ & $\begin{array}{l}(15) \\
(40)\end{array}$ & $\begin{array}{l}25 \\
27\end{array}$ & $\begin{array}{l}(13) \\
(26)\end{array}$ & $\begin{array}{l}7 \\
8\end{array}$ & $\begin{array}{l}(4) \\
(8)\end{array}$ & $\begin{array}{l}36 \\
20\end{array}$ & $\begin{array}{l}(19) \\
(19)\end{array}$ & $\begin{array}{l}4 \\
2\end{array}$ & $\left\{\begin{array}{l}(2) \\
(2)\end{array}\right.$ \\
\hline $\begin{array}{l}\text { 13. Admission } \\
\text { International } \\
\text { American }\end{array}$ & $\begin{array}{l}53 \\
63\end{array}$ & $\begin{array}{l}(28) \\
(60)\end{array}$ & $\begin{array}{l}21 \\
16\end{array}$ & $\begin{array}{l}(11) \\
(15)\end{array}$ & $\begin{array}{l}0 \\
1\end{array}$ & $\begin{array}{l}(0) \\
(1)\end{array}$ & $\begin{array}{l}19 \\
15\end{array}$ & $\begin{array}{l}(10) \\
(14)\end{array}$ & $\begin{array}{l}8 \\
5\end{array}$ & $\begin{array}{l}(4) \\
\text { (5) }\end{array}$ \\
\hline $\begin{array}{l}\text { 14. Campus Mir } \\
\text { International } \\
\text { American }\end{array}$ & $\begin{array}{r}22 \\
4\end{array}$ & $\begin{array}{l}(12) \\
(4)\end{array}$ & $\begin{array}{l}4 \\
7\end{array}$ & $\begin{array}{l}(2) \\
(7)\end{array}$ & $\begin{array}{r}1 \\
11\end{array}$ & $\begin{array}{l}(2) \\
(10)\end{array}$ & $\begin{array}{l}66 \\
72\end{array}$ & $\begin{array}{l}(35) \\
(68)\end{array}$ & $\begin{array}{l}4 \\
6\end{array}$ & $\begin{array}{l}(2) \\
(8)\end{array}$ \\
\hline $\begin{array}{l}\text { 15. Eoreions } \\
\text { International } \\
\text { American }\end{array}$ & $\begin{array}{r}\text { tent } \\
45 \\
3\end{array}$ & $\begin{array}{l}\text { Adviso } \\
(24) \\
(3)\end{array}$ & $\begin{array}{r}* \\
28 \\
5\end{array}$ & $\begin{array}{r}(15) \\
(5)\end{array}$ & $\begin{array}{r}2 \\
21\end{array}$ & $\begin{array}{l}(1) \\
(19)\end{array}$ & $\begin{array}{l}25 \\
64\end{array}$ & $\begin{array}{l}(13) \\
(61)\end{array}$ & $\begin{array}{l}1] \\
7\end{array}$ & $\begin{array}{l}(0) \\
(7)\end{array}$ \\
\hline $\begin{array}{l}\text { 16. Minority } \\
\text { International } \\
\text { American }\end{array}$ & $\begin{array}{r}\text { dent } \\
15 \\
2\end{array}$ & $\begin{array}{l}\text { Affai } \\
(8) \\
(2)\end{array}$ & $\begin{array}{l}9 \\
5\end{array}$ & $\begin{array}{l}(5) \\
(5)\end{array}$ & $\begin{array}{l}11 \\
19\end{array}$ & $\begin{array}{r}(6) \\
(18)\end{array}$ & $\begin{array}{l}62 \\
72\end{array}$ & $\begin{array}{l}(33) \\
(68)\end{array}$ & $\begin{array}{l}2 \\
2\end{array}$ & $\begin{array}{l}\text { (1) } \\
\text { (2) }\end{array}$ \\
\hline $\begin{array}{l}\text { 17. Disabled } \\
\text { Intermational } \\
\text { Anerican }\end{array}$ & $\begin{array}{c}\text { dent } \\
11 \\
3\end{array}$ & $\begin{array}{l}\text { Advis } \\
\text { (6) } \\
(3)\end{array}$ & $\begin{array}{l}4 \\
3\end{array}$ & $\begin{array}{l}(2) \\
(3)\end{array}$ & $\begin{array}{l}15 \\
19\end{array}$ & $\begin{array}{r}(8) \\
(18)\end{array}$ & $\begin{array}{l}68 \\
72\end{array}$ & $\begin{array}{l}(36) \\
(68)\end{array}$ & $\begin{array}{l}2 \\
3\end{array}$ & $\begin{array}{l}(1) \\
(3)\end{array}$ \\
\hline $\begin{array}{l}\text { 18. Career Co } \\
\text { International } \\
\text { American }\end{array}$ & $\begin{array}{c}261 \text { in } \\
26 \\
18\end{array}$ & $\begin{array}{l}\text { Offi } \\
(14) \\
(17)\end{array}$ & $\begin{array}{r}9 \\
14\end{array}$ & $\begin{array}{l}(5) \\
(13)\end{array}$ & $\begin{array}{r}9 \\
10\end{array}$ & $\begin{array}{l}(5) \\
(10)\end{array}$ & $\begin{array}{l}53 \\
56\end{array}$ & $\begin{array}{l}(28) \\
(53)\end{array}$ & $\begin{array}{l}2 \\
2\end{array}$ & $\begin{array}{l}(1) \\
(2)\end{array}$ \\
\hline $\begin{array}{l}\text { 19. Ereshman } \\
\text { International } \\
\text { American }\end{array}$ & $\begin{array}{c}\text { Lenta } \\
28 \\
27\end{array}$ & $\begin{array}{l}\text { tion } \\
(15) \\
(26)\end{array}$ & $\begin{array}{l}17 \\
14\end{array}$ & $\begin{array}{l}(9) \\
(13)\end{array}$ & $\begin{array}{l}13 \\
16\end{array}$ & $\begin{array}{l}(7) \\
(15)\end{array}$ & $\begin{array}{l}40 \\
43\end{array}$ & $\begin{array}{l}(21) \\
(41)\end{array}$ & $\begin{array}{l}2 \\
0\end{array}$ & (1) \\
\hline $\begin{array}{l}20 . \text { Women'sc } \\
\text { International } \\
\text { American }\end{array}$ & $\begin{array}{r}\operatorname{cer} \\
11 \\
3\end{array}$ & $\begin{array}{l}(6) \\
(3)\end{array}$ & $\begin{array}{l}6 \\
4\end{array}$ & $\begin{array}{l}(3) \\
(4)\end{array}$ & $\begin{array}{l}11 \\
18\end{array}$ & $\begin{array}{l}(6) \\
(17)\end{array}$ & $\begin{array}{l}72 \\
69\end{array}$ & $\begin{array}{l}(38) \\
(65)\end{array}$ & $\begin{array}{l}0 \\
6\end{array}$ & $\begin{array}{l}(0) \\
(6)\end{array}$ \\
\hline
\end{tabular}

*Statistically significant at the .05 level. 
professors during of fice hours, and Admissions. International students found two resources to be helpful: other student friends and professors during office hours.

American students found two more resources to be "moderately helpful": Health Center and staff, and Financial Aid. International students found the Writing Center, Admissions, and the Foreign Student Advisor to be "moderately helpful." As international students continue to work with the Admissions office throughout their studies as opposed to American students who cease contact with the Admissions Office upon being admitted, this finding is not surprising.

No resources were found to be unhelpful by either group. Although not statistically significant, Financial Aid also received the highest "unhelpful" score for Americans, and program advisorsreceived the highest "unhelpful" score by international students, closely followed by the "unhelpful" score for the Foreign Student Advisor. These responses are interesting and are unlikely to be the result of a response by American students who were unhappy not to receive financial aid (in which case one might expect that international students would also find financial aid to be "unhelpful" since so few are eligible) or by international students who would naturally have a higher number of "unhelpful" responses to the foreign student advisor since this resouroe is one of, if not the single most important resource provided by the college. In fact, in several instances respondents made unrequired marks on the 
questionnaire to show their displeasure with the resource of foreign student advisor, including short critical comments ("the worst!"), stars, darkened circles, etc., leading to a general impression of dissatisfaction.

Both American and international students recorded $40 \%$ or more "don't know" responses to the following resources: Dean of Student Services, Academic Resource Center, Math Center, Campus Minister, Minority Student Affairs, Disabled Student Advisor, Career Counseling, Freshmen Orientation, and the Women's Center. In addition, American students also recorded $40 \%$ or more "don't know" responses to the resources of the Graduate Office and staff, the Writing Center, Campus Security, Program Advisor, and, as might be expected, Foreign Student Advisor.

\section{Student listed resources}

Respondents were asked to list any of the resources from Section II of the questionnaire from which they would desire more help. Table XIV in Appendix C gives the complete list of resources asked for by students. American students requested the following most often: Financial Aid (10 respondents), Career Counseling ( 8 respondents), and professors during office hours ( 5 respondents). International students made the following requests most of ten: Foreign Student Advisor (15 respondents), Career Counseling (7), and the Graduate Office and Staff (5). It is interesting that Career Counseling received both a high number of requests for more help and 
INTERNATIONAL GTUDENT PERCEETIONS OF RESOURCES BY RANK ORDER

Resource Degree of Helpfulness by Percentage

\section{Exceptionally Helpful}

None

\section{Helpful}

1. Other student friends

5. Professors during office hours

\section{Moderately Helpful}

13. Admissions

15. Foreign Student Advisor

Not Helpful.

None

Not Applicable

None

Don't Know

20. Women's Center

17. Disabled Student Advisor

14. Campus Minister

16. Minority Student Affairs

18. Career Counseling

9. Math Center

3. Dean of Student Services

7. Academic Resource Center

19. Freshman Orientation 


\section{T'ABLE X}

AMERICAN GTUDENT EERCEPTIONS OF RESOUTCE:

BY RAMK ONOER

Resource

Degree of Helptulness by Percentage

Exceptionally Heloful

None

Helpful

1. Other student friends

5. Professors during office hours

Moderately Helpful

6. Health Center and Staff

12. Financial Aid

Not Helpful

None

Not Applicable

None

Don't KnOW

14. Campus Minister

16. Minority Student Affairs

17. Disabled Student Advisor

20. Women's Center

15. Foreign Student Advisor

9. Math Center

18. Career Counseling

7. Academic Resource Center

3. Dean of Student Services

8. Writing Center

11. Program Advisors

10. Campus Security

19. Freshman Orientation

4. Graduate Office and Staff 
a high number of "don't know" responses.

\section{Demographic characteristics}

The following categories were examined to determine if knowlodge of student resources differed between American and international students: freshman were compared to a combination of seniors and graduate students; students who had attended the college for a year or less were compared to students who attended for more than a year; students who lived in college housing were compared to commuters; and students who were involved or somewhat involved in extracurricular activities were compared to students who were uninvolved.

An average number of "don 't know" responses was recorded for each demographic group to provide a comparison between international and American students. No chi square statistic was performed as the sample sizes were too small to be statistically relevant within a significant degree of freedom.

American students had a total higher average of "don 't know" responses than international students. However, when the demographic categories presented in Table XII are examined, international students have a higher "don't know" response in several instances.

Both American and international freshmen had higher "don 't know" responses to "helpfulness" of resources than their senior and graduate student counterparts. However, the difference is greater for international students. For both freshmen and seniors/graduate students, Americans registered more "don 't know" responses than 
international students.

When length of time at SOSC is examined, both American students and international students who attended SOSC for 1 year or less had a higher "don't know" response than students who had attended for more than a year, but international students made a greater change to fewer average "don't know" responses after a year of attendance than American students. International students recorded fewer "don't know" responses than American students in both categories.

Both international and American students who live in college housing show fewer "don't know" responses than American students who commute. International students recorded fewer "don't know" responses in both categories than American students.

International and American students who were involved in extracurricular activities showed fewer "don't know" responses than students who were uninvolved. The biggest gains in knowledge were shown in this category for both groups.

The next largest gain in knowledge for American students were for those who lived in college housing. The smallest gain involved the length of time at SOSC. The second largest gain of knowledge for international students was found in the comparison of seniors and graduate students to freshmen. 
TABLIE XI

DEMOGRAFHIC COMPARISON OF INTERNATIONAL AND AMERICAN

STUDENTS BY KNOWLEDGE OE RESOURCES

Total number of "don't know" responses

N Averase

per student

American students

(854)

8.99

International students

(406)

7.66

Class Level

Ereshmen

Senior/Graduate

\begin{tabular}{lrrrr} 
& $\mathrm{N}$ & Ave. & $\mathrm{N}$ & Ave. \\
\hline American students & $(239)$ & 8.85 & $(207)$ & 8.6 \\
International students & $(98)$ & 8.16 & $(36)$ & 6.6 \\
\hline
\end{tabular}

Length of Time at SOSC

1 year or less

More than 1 year

\begin{tabular}{lcccc} 
& $\mathrm{N}$ & Ave. & $\mathrm{N}$ & Ave. \\
\hline American students & $(389)$ & 9.49 & $(485)$ & 9.33 \\
International students & $(201)$ & 8.38 & $(98)$ & 7.0 \\
\hline
\end{tabular}

Residence

College Housing

Commuter

\begin{tabular}{lllll} 
& $\mathrm{N}$ & Ave. & $\mathrm{N}$ & Ave. \\
\hline American students & $(225)$ & 8.33 & $(843)$ & 9.74 \\
International students & $(100)$ & 7.69 & $(210)$ & 6.4
\end{tabular}

Extracurricular

Not Involved Somewhat/Involved

\begin{tabular}{lcccc} 
& $\mathrm{N}$ & Ave. & $\mathrm{N}$ & Ave. \\
\hline American students & $(515)$ & 10.05 & $(354)$ & 3.42 \\
International students & $(95)$ & 9.5 & $(217)$ & 7.75
\end{tabular}

*The total number of "don't know" responses possible for each student is 20 , one for each resource. 


\section{SECTION III}

\section{English Language Proficiency}

Of the 53 international students sampled, 9 had not taken the TOEFL. Forty-four reported TOEFL scores which ranged from 3 between $400-450,4$ between $451-500,25$ between 501-550, 7 between 551-600, and 4 over 600. In order to create large enough sub-groups withinthe range, the scores between 400 and 500 were considered together and the scores above 551 were considered together.

In their self-reported academic English language proficiency, international students ranged their abilities from a score of 1 (poor) to 4 (good) in 8 areas. The highest possible score for each student was 32 ; the lowest possible was 8 . Nine students scored themselves in the range of $16-20,10$ students scored themselves in the range of $21-23,10$ students scored themselves in the range of 24 26,13 students scored themselves in the range of $27-29$, and 11 students ranged themselves between 30 and 32 .

The TOEFL scores and self-reported scores did not correlate highly either on the high or low end of the ranges. For example, one of the 4 students scoring over 600 on the TOEFL provided a self-score of 21, one of the lowest scores. Conversely, one of the studente who scored between 400 and 450 on the TOEFL self-scored a total of 32 , the highest possible score. Since most TOEFL scores did range in the middle group (501-550) and most of the self-reported scores ranged in the middle three groups, these tended to correlate more highly. 
TABIE XII

PELATTON BETHEEN SELF-REPORTED ENOLISH DROEICIENCY

AND EXTENT TO WHICH NEEDS ARE MET EDE

TNTERAATTONAL STIDENTS

\begin{tabular}{lrrrrrrrrrrrr}
\hline Range & 32 & -30 & 29 & -27 & 26 & -24 & 23 & -21 & 20 & 16 \\
& $\%$ & $N$ & $\%$ & $N$ & $\%$ & $N$ & $\%$ & $N$ & $\%$ & $N$ \\
\hline Met* & 42 & $(97)$ & 48 & $(131)$ & 41 & $(90)$ & 42 & $(90)$ & 26 & $(54)$ \\
Unmet* & 33 & $(33)$ & 26 & $(72)$ & 39 & $(82)$ & 36 & $(83)$ & $58(10)$ \\
Don't Know* & $5.6(13)$ & 15 & $(42)$ & $3.8(8)$ & 8 & $(17)$ & $2.6(5)$ \\
\hline
\end{tabular}

TABLE XIII

RELATION BETWEEN SELF-REPORTED TOEFL SCORE AND EXTENT TO WHICH NEEDS ARE MET FOR INTERNATIONAL STUDENTS

\begin{tabular}{|c|c|c|c|c|c|c|}
\hline \multirow[t]{2}{*}{ Range } & \multicolumn{2}{|c|}{$400-500$} & \multicolumn{2}{|c|}{$501-550$} & \multicolumn{2}{|c|}{551 - over 600} \\
\hline & $\%$ & $N$ & $\%$ & $\mathrm{~N}$ & $\%$ & $\mathrm{~N}$ \\
\hline Met* & 33 & $(42)$ & 46 & (241) & 35 & $(82)$ \\
\hline Unmet* & 44 & (56) & & (205) & 35 & $(81)$ \\
\hline Don't Know* & 3.1 & (4) & 9.3 & (49) & 8.2 & (19) \\
\hline
\end{tabular}

*Responses are totaled from the 21 objectives for each group. 
Table XII shows the numbers and percentages for self-reported English proficiency in relation to the Need Index. The values shown are "Met," "Unmet," and "Don't Know." "Not Applicable" and "Not Needed" do not appear as the numbers, although part of the total percentage, were not relevant.

The TOEFL scores do not have a computational correlation with the extent that needs are met for international students. The highest range of scores has percentages of met and unmet needs which are equal, and which are both lower than the range of scores which fall in the middle scoring group, 501-550.

The self-reported proficiency scores more closely correlate with an index of met and unmet needs. If the ranges were collapsed from five categories to 3 , the correlation would be even stronger. The lowest self-reported scores clearly correlate with the highest. percentage of unmet needs and the lowest percentage of met needs.

\section{SECTION IV \\ Summary of Eindings}

The importance of objectives were first examined for significant differences, with responses for three of the 21 objectives found significantly different when American students were compared to international students. While most students in both groups saw the majority of objectives as "important," differences existed in degree 
of importance. Both international and American students agreed on 3 of the top 5 individual objectives as the most important. The ranking of objectives provided more detailed findings than did the Chi square statistical analysis. According to the rankings, Anerican student rankings reflected the highest percentages of "important." The effectiveness of the objectives was also examined. Significant differences occurred in the responses for eleven of the objectives when examined by categories of "effective," "not effective," "not applicable," and "don't know." The rank ardering of responses provided more detailed information and further clarifies the pattern of responses. International students found 9 of the objectives to be "effective" and 4 of the objectives to be "moderately effective," which comprise more than half of the objectives. For the American students, approximately half of the objectives were found to be "effective" (7) or "moderately effective" (4). International students found 3 of the objectives "ineffective," and American students found 1 of the objectives "ineffective" and responded with "don't know" at higher than $40 \%$ to one objective. International and American students agreed on the positive effectiveness of the three highest-ranking objectives, including providing a balance of social, cultural, and recreational activities, helping students to develop their educational and career goals, and providing opportunities for students to receive individual help if they need it.

The needs of students regarding objectives were established 
through a combined analysis of the importance and effectiveness of objectives. When this need index was applied to the objectives, 9 of the 21 were considered "fulfilled" or "moderately fulfilled" for the international students, and 11 of the objectives were considered "fulfilled" or "moderately fulfilled" for the American students. Both groups ranked the same three objectives as most highly fulfilled: developing educational and career goals, a balance of social, cultural and recreational activities, and individual help provided if needed. The need index revealed that international students and American students identified different objectives which were unfulfilled, with international students identifying six unfulfilled needs and American students identifying only one. The three most unfulfilled needs identified by international students focused on awareness of the values of others, relating to others, and the atmosphere on campus being conducive to intellectual growth.

Resources available to students were analyzed and significant differences in the responses from the American and international students were found for five of the twenty resources between the two groups. The largest categories of inportance were responses of "don't know," where both groups indicated they did not know about some of the services designed to serve a particular segment of the student body, such as the Disabled Student Advisor, Minority Student Affairs, and the Foreign Student Advisor. The Women's Center was also found to be unfamiliar to the respondents, as was the Campus Minister, which is not surprising in that Southern Oregon State 
College is a public institution with no religious affiliation. The "not helpful" ratings were not significant enough to appear in the rating scales.

Several categories among the demographic characteristics were correlated to the number of "don "t know" responses in the list of resources to determine whether Americans and international students differed in their knowledge of resources based on how long they had attended the college, what their class level was, whether they lived in campus housing and how involved they were in extracurricular activities. The highest correlation of knowledge was establj.shed with senior and graduate level international students. In each case, international students showed slightly fewer average "don't know" responses than American students.

English language proficiency of international students, measured both by self-reported TOEFL and a self-reported academic rating scale, were correlated with met and unmet needs as provided by the need index of objectives to establish that there was some correlation with the self-reported proficiency scores but no correlation with the TOEFL scores. The strongest correlation occurred with the lowest self-reported scores and the highest number of unmet needs. 
CHAPTER V

DISCUSSION

The purpose of this study was to determine the effectiveness of student services for international students at Southern Oregon State College and to identify their needs for student resources. A secondary purpose was to determine whether the effectiveness of and needs for student services for international students differed from those of American students, and whether English language proficiency was a factor.

Three null hypotheses were examined for statistical significance of the data. The first was that no significant differences would be found between American and international students in how they

perceived the importance of the objectives of student services. The second was that no significant differences would be found between American and international students in how they perceived the effectiveness of student services. The third was that no significant differences would be found between American and international students in how they perceived the helpfulness of various student resources available at $\mathrm{SOSC}$. The Chi-square statistical analysis was used to determine significant differences, with the level of significance at the .05 level.

Each trypothesis was examined further for direction and degrees of differences between American and international students based on a 
rank order of percentages.

In order to define student needs for services suggested by the objectives, an index was established based on the "importance" and "effectiveness" responses. These needs were rank ordered in order to assess their relative value.

Self-reported English language proficiency of international students was correlated with the extent of fulfillment of needs according to the index.

\section{Eindings}

The null hypotheses were rejected at the .05 level, and differences were found between American and international students for several objectives of student services and resources available to students outside of the classroom. Very few differences were found in examining the demographic characteristics.

\section{Importance of objectives}

Responses to three of the twenty-one objectives were significantly different when American students were compared to international students. While most students in both groups saw the majority of objectives as "important," differences existed in degree of importance placed on these objectives by the respondents. The international students gave greater support to the objectives than the American students. 
The objectives "to develop educational and career soals" and "to give individual help if needed" appeared to be of Ereatest importance for the entire college, for they ranked in the top two or three objectives for both groups.

Other objectives which were also strongly affirmed by international students were "to develop a system of values," "to develop decision-making skills," and "awareness of the needs of individuals."

\section{Effectiveness of Objectives}

Responses to eleven objectives were found to be statistically significantly different when American and international students were compared. This outcome was based on the four response categories of "effective," "not effective," "not applicable," and "don t know."

The international students rated the following nine objectives "effective": developing educational and career goals; developing leadership and organizational skills; a balance of social, oulturol, and recreational activities; availability of individual help; $a$ campus atmosphere conducive to the personal growth of students; counseling for students with personal concerns; orientation of new students; information about the availability of student services, and encouragement to use the available student services. Four objectives were found to be moderately effective, including understanding selves as individuals, developing decision-making skills, participating on decision-making committees, and clearly defining the policies and 
rules of the college.

Americun student responses indicated the 7 following objectives were seen as "effective," according to rank order in Table V: a. balance of social, cultural, and recreational activities; availability of individual help; developing educational and career goals; a campus conducive to intellectual growth; a campus conducive to personal growth; clearly defined college policies and rules, and relating to one another. The 4 "moderately effective" objectives were developing decision-making skills, awareness of the values held by others, developing leadership and organizational skills, and participation on decision-making committees.

The three objectives found to be ineffective by international students were developing a system of values, awareness of the valines held by others, and a campus atmosphere conducive to the intellectual growth of students. The objective of providing information about the available student services was found to be "ineffective" by Arterivan students.

International and American students had similar rankings of the top three effective objectives: to provide a balance of social, cultural, and recreational activities; to develop educational and career goals; and to provide individual help if needed.

While American students found only one objective to be ineffective--concerning providing information about the available student services--international students found three objectives ineffective, two of which related to awareness of values held by 
others and one concerning the campus atmosphere being conduoive to intellectual growth. This seems to indicate a higher conoem with cultural differences, as might be expected of international students.

\section{Needs of students}

According to the need index, needs were fulfilled for seven of the objectives for international students. In rank order, the international students found the same top three objectives as noted in the "effectiveness" rankings to be fulfillad; these were also the same top three ranked by American students. That students found three of the most important needs to also be the three most effective needs shows a measure of fulfillment at SOSC which is positive. The other needs found to be fulfilled were: participation on decisionmaking committees, orientation of new students, developing leadership and organizational skills, and a campus atmosphere conducive to personal growth. The following needs were considered to be "moderately fulfilled": clearly defined college policies and rules and developing decision-making skills.

American student needs were met for six of the objectives, which were: (listed in order of highest percentage first) individual help available if needed; a balance of social, cultural, \& recreation activities; developing aducational and career goals; a campus conducive to intellectual growth, clearly defined college policies and rules, and developing decision-making skills. The need for five objectives was moderately met. These include a campus conducive to 
personal growth, developing leadership and organizational skills, relating to one another, awareness of the values of others, and encouragement to use student services.

International students differed significantly from American students in the number of needs which were not fulfilled. American students found only one need unfulfilled, to provide information about student services. International students found six needs unfulfilled; the top three related again to awareness of values and relating to one another and a fourth again identified the campus as not being conducive to intellectual growth.

\section{Helpfulness of resources}

While significant differences existed in respondent groups of American and international students for five of the twenty resources, the two groups reflected some similarity in their responses. The differences noted in "helpfulness" are in the categories of residence hall staff, health center and staff, writing center, financial aid, and foreign student advisor.

The largest categories of similar responses for both groups were responses of "don't know" for resources which applied only to specific groups. The "not helpful" responses were few in number. The resources of student friends and professors during office hours were found to be the most helpful for both groups. Americans also found Admissions to be helpful. International students identified the Writing Center, Admissions, and the Foreign Student Advisor as 
moderately helpful. These rankings are of interest as the writing Center was ranked among the "don't know" resources for Anericans. In addition, "not helpful" responses by international students to the resource of Foreign Student Advisor reflected the second highest. total of all "not helpful" responses. This may be data which should be examined by the Foreign Student Advisor at SOSC.

Some of the resources which international students ranked significantly in the "don't know" category could be of concern: the Academic Resource Center provides a number of important campus services including counseling, career counseling and placement, academic advising, and remedial workshops. And Freshman orientation was also ranked significantly in the "don't know" category. If this resource were expanded and used more pervasively, it could affect students' knowledge of all the other resources found in the "don't know" category. The Math Center was also found in this category; this may be due to the fact that it is a relatively new (this academic year) resource on campus.

\section{Demographic characteristics}

Several demographic categories were correlated with the "don't know" responses on the list of resources available for each student in that category. The number of "don't know" responses decreased for seniors and graduate students when compared to freshmen. The number also decreased for students who were more involved with extracurricular activities. Of interest was the higher total number 
of "don't know" responses for Americans in conparison with

international students. This seems to indicate that internations?

students may be better informed about student resources than Anerican

students. A number of factors may affect this.

\section{English language proficiency}

Self-reported TOEFL score did not demonstrate a computational correlation with the fulfilled and unfulfilled needs of internations.l students. However, self-reported language proficiency as indicated by a scored scale of eight abilities did correlate to some extent, especially at the low end of the scale, where international students who scored themselves as least proficient were much more likely to have more unmet needs and fewer "fulfilled" needs.

\section{Conclusions and Implications}

Both American and international students considered most of the objectives important and found that approximately one-third of the services were successfully meeting the needs of the students. The fact that both American and international students registered few "needs unfulfilled" responses and yet admitted a lack of know]edge concerning several resources may indicate that the students are not as critical in their responses as they might have been had they more knowledge. Those objectives which were considered "exceptionally important," yet unclassified as regard to degree of fulfillment, 
should be considered as areas needing attention and possible improvement.

The personal involvement of faculty, advisors, and oftices which serve the students directly seem to be helpful to students, as indicated in the responses to resources. The smallness of the college and noted friendliness of the students may be reflected in the high responses of helpfulness for the resource of student friends.

The unfulfilled need by American students for more information about the available services would seem to coincide with the students' lack of knowledge about the available resources of counseling center, career counseling, Women's Center, and Freshman Orientation. Women responded with an overall. "don't know" to the resource of Women's Center. It was expected that female students would and should be aware of a service designed to be helpiful to them. An implication might be the lack of sufficient support for this service which has only been expanded recently and which may need to increase its visibility.

Other resources which were unfamiliar to both American and international students included campus minister, Dean of Student Services, Minority Student Affairs, and Disabled Services. Each of these resources provides services to a select population at the college for a select reason. One would expect that a visit to the Dean of Student Services would not be a common occurrence for a student. Few minority students attend Southern Oregon State College, 
and the location of the office serving them is out-of-the-way. This is also the case with Disabled Services.

International students found the Writing Center effective, yet American students responded overall in the "don 't know" category. There are two possible factors at work here; the instructor of the protected international writing courses has her office inside the entrance to the Writing Center, necessitating that students who visit her locate the Center; and the former instructor of the protected international writing courses is now the director of the witing Center, which makes it particularly "user-friendly" for international students. In comparison, the international students along with American students responded most highly in the "don't know" category regarding the resource of the Math Center, even though a majority of international students are likely majoring in the sciences.

International students gave more "unhelpful" responses to the resource of Financial Aid, which might be expected, since funds are limited for non-residents. American students identified this resource as among the most helpful.

The Academic Resource Center was identified overall in the "don't know" category for both international and American students. Since this Center provides a variety of services to students, attention may need to be devoted to attracting more students. It would be interesting to discover the actual numbers of students served by the Center; during four visits it was found to be quiet and relatively deserted although staffed with several helpful and 
attentive personnel.

When developing the instrument, it was thought the demographic categories of age, sex, major, year in school, residence, length of time at SOSC, and involvement in activities would reveal differences in perceptions of importance or effectiveness. In reality, however, these characteristics made little difference in the outcome of the investigation. In a larger sample of students, these demographic categories may have revealed more interesting results.

The major strengths of this instrument were reflected in the measures of importance and effectiveness, since these represent the difference between an existing condition and a desirable condition. From a combination of these two measures, met and unmet needs can be discerned.

Although the list of resources is not directly related to the importance and effectiveness measures, it provided additional information about the helpfulness and knowledge of existing services.

The factor of English language proficiency was difficult to relate to any of the results. The comparison was forced and a more relevant method of correlating language proficiency with use of student resources was desired.

An important consideration for Southern Oregon State College is the attitude of international students that the objectives of developing awareness of the values of others and learning to relate to other students were ineffective. International students also found the campus atmosphere to be ineffective in adding to the 
intellectual growth of students. The college must examine why international students identify these objectives as ineffective and what may be done to improve the status of these objectives. This may be a key element to the satisfaction of international students with their educational experience at Southern Oregon State College and in the United States.

A final conclusion drawn from the results of the study is the Southern Oregon State College is faced with the challenge of increasing the publicity of its services to students and encouraging its student body to utilize these services.

\section{Comparison of Results with Agler's Study}

Since the instrument developed in this study in some places closely resembles the instrument used by Agler (1980), it is interesting to note that several similarities in responses were identified, even over a time period of sixteen years. Respondents in Agler's study and at SOSC found all the objectives to be important and almost equal numbers of objectives to be effective. Exactly the same number of objectives were found to be helpful for American students as well as international students. The two most helpful resources identified by Agler's respondents were "student friends" and "professors outside of the classroom." A high number of "don't know" responses were recorded for most of the same resources at 
Agler's University of La Verne and at SOSC, indicating a need for improved knowledge of resources on both eampuses. Further studios can provide data as to whether this is a generally occurring situation. As with Agler, the most interesting demographic characteristics indicated involvement with extracurricular activities.

One notable difference between Agler's study and the study at SOSC is that Agler found significant differences in the effectiveness of all 24 objectives between her three groups under scrutiny. 'The SOSC study found only eleven significant differences in effectiveness between international and American students. The fact that she used three groups instead of two likely contributed to this difference.

Agler focused on comparing undergraduates, graduates, and Law School students at the University of LaVerne. She did note demographic data identifying international students, but found it interesting only when discussing the resource of the Foreign Student Advisor. Agler did not attempt to assess English language proficiency as a factor in her study.

\section{Recommendations}

The data analyzed in this study indicate that Southern Oregon State College might consider the following recommendations:

1. Continue to provide the services which relate to objectives in the survey, doing further analysis of those objectives which 
fajled to be categorized in the need index. Particular emphasis should be placed on those objectives which were considered "exceptionally important" for both groups but did not qualify to be categorized in the need index. For international students, these are: college awareness of individual needs, information about available student services, colunseling for personal concerns, campus climate conducive to intellectual growth, relating to one another, understanding selves as individuals, awareness of values held by others, encouragement to use available student services, applying leadership and organizational skills, and developing a system of values. American students also found most of these objectives "exceptionally important" and many of them did not qualify for the need index. Two additional objectives which American students found "exceptionally important" and which did not qualify are orientation of new students to the campus and opportunities to participate on decision-making committees. It should be noted that for both American and international students, the first three ranking "exceptionally important" objectives are being met.

2. Provide more information to both international and American students concerning the available student resources. More specific suggestions follow:

a. A periodic questionnaire in the campus newspaper assessing students' knowledge of student services might serve to increase knowledge.

b. Provide more information during Freshman Orientation in 
particular, and consider expanding Orientation services to nowe then one academic quarter. Consider using an item on quarterly course registration forms which would identify whether new students have had access to Freshman Orientation.

c. Provide more information to freshman undergraduates in particular. Perhaps a one-page directory of what resources are available on campus condensed from the student handbook would assist in locating services. I'his information could be made available when students first arrived on campus.

d. Provide more information to international students in particular. In addition to the resource directory suggested above, newly arriving international students could be presented with a guide to American college life including common procedures and behaviors both in and out of the classroon. Investigate the extent to which the foreign student advisor is helpful in this area.

e. Publicize the services offered by the Acadenic Resource Center in such a way that more students are aware of all the resources available. Several respondents requested more help from Career Counseling, yet this was one of the resources which ranked most highly in the area of "don ' $t$ know" responses.

\section{Limitations of the study}

A broader sample of both international and especially American students would have provided more detailed data in the area of demographic characteristics. Since 38 of the 53 international 
students sampled were contacted through the protected writing classes, the sample was not completely randon. These students represent a level which, although fully admitted, has been gradud remedial in the area of writing skills, with a possible result of a skewed representation of international students. In addition, 35 of the 53 international students had been on the SOSC canpus for 1 year or less. Aithough all respondents had been attending for at least one full quarter before the present one surveyed, it is logical that students who are new to a campus will be familiar with fewer of its resources. In a random sample there is little guarantee of establishing a balance of students demographically in such an area as this one, but surveying the protected courses probably introduced more recent students more heavily.

Because of the concurrent survey conducted by the Office of Student Affairs for the upcoming accreditation, the number of classes which were available for samples was limited to those which were not already chosen for the College Outcomes Survey. Therefore a truly random sampling of students was not possible in the time frame allowed for the research.

The comparison of English language proficiency with unmet and met needs for student services by international students has an incomplete theoretical background and was constructed in great part for this study. No claim is made for its significance. More research needs to be done to determine whether this is a reliable instrument for this portion of the survey. 
The "halo effect," in which respondents tend to react positively in order to please others, may be a factor in the survey. This is always a consideration when conducting survey research; the opposite effect may also be true. To clarify, several of the surveys were completed in which the respondent answered in exactly the same way for every single objective. In some cases, the respondent marked that every objective was "Very Important" and "Very Effective." In other cases, the respondent marked "Don "t know" for the effectiveness of every objective. In question is the amount of thought the respondent put into marking each answer.

Some terms were changed, upon the advice of personnel at Southern Oregon State College, to ensure comprehension by international students. The most important change was the term "well" substituted for "effectively." The connotations are slightly different and, although the survey is consistent within itself, the intent of the question as designed by Agler and McDavis may be subtly altered.

Another term of concern was "not applicable." Although this term was explicitly explained in each class where the questionnaire was distributed, so many seemingly inappropriate "not applicable" responses were recorded by international students that there emerges the possibility that this term was defined as a negative one on a scale with "poorly" or "not effective."

Respondents were requested to make some kind of mark for each objective and resource to avoid missing data. But in several cases 
surveys were left partially or alnost completely unanswered and were in effect useless except to raise the issue of why they had been left unanswered: comprehension problems? disinterest? oversight? time constraint? personal issues?

As content validity was not thoroughly assessed either in Agler's study or the study at SOSC, how the terms used were perceived by each group of respondents is unknown. In particular, the idea of "values" and the vocabulary needed to understand the objective of "a campus atmosphere with adds to the intellectual growth of students" are suspect. If the terminology was perceived in different ways by different students, how can we really know what significant differences in effectiveness imply about non-native English speaking students?

\section{Suggestions for revision of the questionnaire}

1. Demographic characteristics should be de-emphasized, and more emphasis should be placed on measures of involvement, such as on-campus living and involvement in activities, since the results indicated a correlation between involvement and knowledge.

2. Students should be given the opportunity to indicate if they are local or from out of the area. This characteristic may affect familiarity with resources since SOSC interacts with the local high school on several levels.

3. Revise the wording for objective 12 , "to participate on decision-making committees," and objective 21 , "to provide 
disciplinary actions which are growth experiences," since a large number of "don't know" and "not applicable" responses indicate that these objectives may be unclear. Consider deleting objective 3 , "to develop a system of values," due to issues of cultural differences and possible misunderstanding of vocabulary.

4. Provide sub-categories for the resource of Academic Resource Center, so that students will have an opportunity to be more clear about how helpful all of the services provided have been. These include personal counseling and remedial workshops as well as career and academic counseling.

5. If given to another population, the resources outside of the classroom should be restricted to those appropriate for each institution.

6. Create a stronger measurement to correlate demographic characteristics with knowledge of student services.

7. Determine a stronger means of measuring a correlation between English language proficiency and use of student services.

8. Ensure that sampling of classes is random to allow more balanced representation of such important demographic variations as length of time on campus and level of class standing.

9. Consider conducting a limited number of follow-up interviews with respondents who wish to participate in order to determine that the language used in the objectives was comprehended and that answers given corresponded to the intentions of the respondents. 
Suggestions for further research

At Southem Oregon State College itself, the international students could be interviewed both individually and in groups to determine what factors are affecting their use of student services and the effectiveness of objectives relating to values, relationships, and a campus atmosphere conducive to intellectual growth. It would be interesting to measure their experience at SOSC on a satisfaction scale compared to American students.

A second study focusing only on the most important and effective objectives and resources at Southern Oregon State College based on the findings of this study could endeavor to reveal more detailed differences in the use of student services by American and international students. For instance, the fulfilled need for the objective of a balance of social, cultural, and recreational activities could be expanded to look at a number of activities offered in each area, especially in the area of cultural activities.

More useful would be a study focusing only on the differences between international and American students as far as the importance and effectiveness of objectives. In addition, a study which examined a larger pool of strictly international students could search for a relationship between types of responses and home country. During a first holistic examination of the completed questionnaires, an impression arose of a correlation between Japanese female respondents and positive responses.

As this instrument has been revised for use in comparing the 
experiences of international. students and American students for the first time, it would be aseful to determine whether another institution would have similar results with the same revised instrument. As little research has been done in the area of measuring the use of student services by international students, such a study would add to the literature in this area.

A comparison of available student services at colleges and universities in other countries with American student services might reveal underlying philosophical differences about what resourcess and objectives are important factors in a college education. These differences, if they were found to exist, could help to explain difficulties international students may have in using student services in the United States.

Many resources are provided by student services at other institutions which are not offered at SOSC. It would be interesting to survey students, both American and international, to determine if their unmet needs would be satisfied by resources on a more comprehensive list than one limited to those offered at SOSC. If this were found to be the case, then additional resources could be suggested to SOSC or other institutions in which students took part in such a survey. 
REFERENCES

Agler, S. K. (1980). An Assessment of the Needs of Student Services at the University of La Verne. Ed.D. Dissertation, University of La Verne.

American Psychological Association (1994). Publication Manual of the American Psychological Association, (4th ed.). Washington, D. C.: Author.

Arbuckle, D. S. (1953). Student Eersonnel Services in Highe: Education, New York: McGraw-Hill.

Berry, M. A. (1967). Campus culture: A product of its own history, The Journal of College Student Personnel. III, 3.

Blaesser, W. W. (1954). Organization and administration of student-personnel programs in college, Review of Educational Research. 24, 113-120.

Brumbaugh, A. J. and L. C. Smith. (1932). A point scale for evaluating personnel work in institutions of higher learning, Religious Education. $27,230$.

Brunson, M. A. (1959). Guidance: An Integrating Brocess in Higher Education. New York: Bureau of Publications, Teachers College, Columbia University.

Canseco, G. and P. Byrd (1989). Writing required in graduate courses in business administration, TESOL Quarterly, 23, 305-316.

Collier, V. P. \& W. P. Thomas (1989). How quickly can immigrants become proficient in school English? Educational Issues of Language Minority Students, 5, 26-38, edited by J. Fuhriman. Boise, Idaho: The Bilingual Education Teacher Preparation Program.

Cowley, H. H. (1931). A technique for making a student personnel survey, Personnel Journal. 10. 17-26.

Cummins, J. (1981). Age on arrival and immigrant second language learning in Canada: A reassessment. Applied Linguistics 2. 132-149.

Dubin, F. (1983). How to Succeed in Your College Courses: A Guide for the ESL Student, Association of American Publishers, New York, NY, 17 pages. ERIC ED 240858. 
Educational Testing Service. (1990) TOEFL I'est and Score Manua 1. 1390-91. Princeton, New Jersey.

Flack, M. J. (1976). Results and effects of study abroad, The Annals of the American Academy of Eolitical and Social Science, 424, 107-117.

Graham, J. G. (1987). English language proficiency and the prediction of academic success, TESOL Quarterly, 21 , 505-521.

Greis, N. (1984). Integrating ESL and academic studies. Evaluative/Feasibility Report, Portland, OR: Portland State University. ERIC ED 250920.

Hargett, G. R. \& S. G. Olswang (1984). An institutional approach to improving the linglish proficiency of Loreign students: The modified transitional model, American Language Journal, 2, 67-83. ERIC ED 248692.

Hopkins, L. B. (1926). Personnel administration in colleges. Educational Record. 7. 174-177.

Hull, W. F., IV. (1978). Foreign Students in the United States of America: Coping behavior within the educational environment. New York, New York: Praeger Publishers.

Johnson, D. C. (1971). Problems of foreign students. International Educational and Cultural Exchange, 7, 61-68.

Kamn, R. B. (1955). How effective are our student personnel programs? Eersonnel and Guidance Jounnal. 33. 318-324.

Klein, M. H., A. A. Alexander and K.-H. Tseng. (1971). The foreign student adaptation progran: Social experiences of Asian students, International Cultural and Educational Exchange, 6, 77-90.

Lee, M. Y., M. Abd-Ella and L. A. Burks, Needs of foreien students from developing nations at U.S. colleges and universities, ed. by Stephen C. Dunnett, National Association for Foreign Student Affairs, Washington D.C., 1981.

Lewis, C. L. (1973). College student personnel: A current estimate, Journal of College Student Personnel. 14. 5-9.

Light, R. L., M. Xu, and J. Mossop. (1987). English proficiency and academic performance of international students. TESOL Quarterly. 21. 251-261.

Maxwell, M. J. (1974). Foreign students and American academic ritual. Journal of Reading, 17 , 301-305. 
MoDavis, R. J. (1974). The Development and Validation of an Instrument to Evaluate Student Personnel Servises in Colloges and Universities. Ph.D. dissertation, University of Toledo.

MoIntyre, J. P. (1974). Student personnel: The challenges of the future. National Association Wonen Deans and Counselors. 38. $59-$ 84 .

Middlebrook, G. C. (1991) Evaluation of student services in ESL programs. Building Better English language programs: Perspectives on evaluation in ESL, Martha C. Pennington, ed., NAFSA: Asssociation of International Educators. ERIC ED 331285.

Morris, R. T. (1960). The Two-Way Mirror: National Status in Eoreign Students' Adjustment. Minneapolis: University of Minnesota Press.

Nenyod, B. (1975). Analysis of problems perceived by foreign students enrolled in state colleges and universities in the state of Texas. Ph.D. Dissertation. East Texas State University.

Ostler, S. E. (1980). A survey of academic needs for advanced ESL, TESOL Quarterly, 14, 89-502.

Spaulding, S. and M. J. Flack. (1976). The World's Students in the United States: A Review and Evaluation of Research on Eoreign Students. New York, New York: Praeger Publishers.

Southern Oregon State College Catalog, 1995-1996. (1995). Publications Office, Southem Oregon State College, Ashland, Oregon.

Tanaka, M. (1994). A Survey to Understand the Situations of Eoreign Students at Southern Oregon State College. Student paper, Southern Oregon State College.

Ursua, A. R. (1969). The relationship between adeptness in the English language and social adjustment of foreign students. Ph. D. dissertation. Catholic University of America.

Walter, J. H. (1978) Counseling Appropriateness: An Exploration from a Cross-Cultural Perspective. Research in Education. ED 159751 .

Verts, L. J. (1994). Integration of ESL/LEP Students in the University. Paper presented at the Sixth TESOL Summer Meeting, Corvallis, OR. 
Walter, J. H. (1978). Counceling Appropriatoness: An Exploration from a Cross-Cultural Eerspeetive. Paper presented at the Speech Communication Association Summer Conference on Intercultural Commuication, Tampa, Florida. ED 159751.

Wrenn, C. G. (1951). Student Personnel Work in Colleges. New York: Ronald Press.

Wrenn, C. G. and R. B. Kamm. (1948). A procedure for evaluating a student-personnel program, School and Society 67, 266-269. 


\section{APPENDIX A}

STUDENT SERVICES QUESTIONNAIRE 


\section{SURVEY OF SERVICES FOR STUDENT'S}

Southern Oregon State College, 1996

The furpose of this study is to obtain your opinion of some of the services offered to students utside of the classroon at Southern Dregon State College. The information collected from the survey will be very helpful. Your honest responses to the statements are essential to this study. This survey is anonymous.

$$
S E C T I O N I
$$

The purpose in this part of the survey is to determine whether or not the university is achieving its goals in the area of services to students. There are two parts to each question. Please check one response for each part of the question.

Part 1 asiks you how important this goal is at your level ifreshman, sophomore, junior, or senior) of a university education.

Bart 2 asks you how well you feel this goal is performed at your level (freshman, sophomore, junior, or senior) at Southern Oregon State College.

$$
\text { SAM } \perp \text { E }
$$

SOSC provides services which help students to develop their career goals.

How important, is

this service to

COSC students?

Very important

Important

of little importance

Not important
How well is this

service pertormed?

Very welz

idel?

Not very weil

Poorly

Not app ícable

Don 't know 
SURVEY OF SERVICES FOR STUDENTS

Southern Oregon State College, 1996

1.

How important is

this service to

SOSC students?

Very important

Important

Of little importance

Not important

2.

How important is

this service to

SOSC students?

Very important

Important

Of little importance

Not important

\section{3.}

How important is

this service to

SOSC students?

Very important

Important

Of little importance

Not important

SOSC provides opportunities which help students develop decision-making skills.

SOSC provides opportunities which help students understand themselves as individuals.

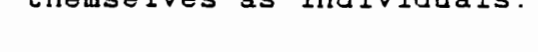


6.

How important is

this service to

SOSC students?

Very important

Important

of little importance

Not important

7.

How important is

this service to

SOSC students?

Very important

Important

of little importance

- Not important

8.

How important is

this service to

SOSC students?

Very important

Important

of little importance

Not important

9.

How important is

this service to

SOSC students?

Very important

Important

Of little importance

Not important

10.

How important is

this service to

SOSC students?

Very important

Important

of little importance

Not important

SOSC provides services

wich help students to

develop their educational

and career goals.

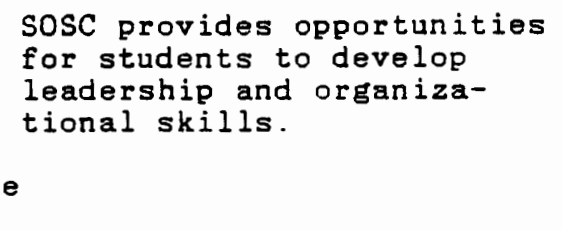


11.

How important is

this service to

SOSC students?

Very important

Important

of little importance

Not important

12.

How important is

this service to

SOSC students?

Very important

Important

Of little importance

Not important

13.

How important is

this service to

SOSC students? Very important

Important

Of little importance

Not important.

14 .

How important is

this service to

SOSC students?

Very important

Inportant

of little importance

Not important

SOSC provides advice for student organizations.

for students to receive individual help if they need it.

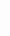

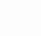

SOSC provides opportunities
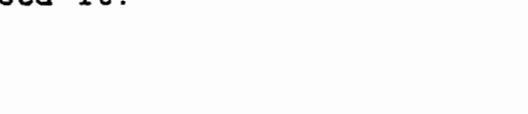

SOSC helps to develop a campus atmosphere which adds to the intellectual growth of students.
SOSC helps to develop

a campus atmosphere which adds to the personal growth of students.

15.

How important is

this service to

SOSC students?

Very important

Important

Of little importance

Not important

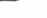

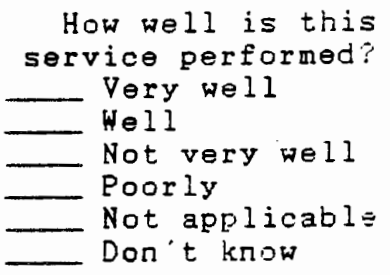

How well is this service performed? Very well

Well

Not very well

Poorly

Not applicable

Don't know

How well is this service performed? Very well Hell Not very well Pooriy Not applicable Don't know

How well is this service perforined? Very well We 11 Not very wa!? Poorly Not applinable? Don't know

How well is this SOSC provides counseling for students with personal concerns. service performed? Very well

Well

Not very well

Poorly

Not applicable

Don " $t$ know 
16.

How important is

this service to

SOSC students?

Very important

Important

Of little importance

Not important

17.

How important is

this service to

SOSC students?

Very important

Important

Of little importance

Not important

18.

How important is

this service to

SOSC students?

Very important

Important

Of little importance

Not important

19.

How important is

this service to

SOSC students?

Very important

Important

of little importance

Not important

20.

How important is

this service to

SOSC students?

Very important

Important

Of little importance

SOSC provides information to students about the available student services.

SOSC orients new students to the campus to make them feel like they are a part of the college. of the individual needs of students.

SOSC encourages students to use the available student services.

SOSC clearly defines the policies and rules of the college.
How well is this service performed? Very well

WeIl

Not very well

Poorly

Not applicable

Don't know

How well is this service performed? Very well Well Not very we?l Poorly

Not applicable Don't know

How well is this service performed? Very well Well

Not very well Poorly

Not applicable Don't know

How well is this service performed? Very well

Well

Not very well

Poorly

Not applicable

Don't know

How well is this service performed?

Very well

Well

Not very well

Poor $1 y$

Not applicable

Don't know 
21

How important is

this service to

SOSC students?

Very important

Important

of little importance

Not important
SOSC provides disciplinary actions which help students

to grow.

How well is this service performed? Very well We 11

Not very well Poorly

Not applicable

Don't know 
$S$ E C T I O N I I

RESOURCES FOR STUDENTS OUTSIDE OF THE CLASSROOM

This section asks you where you yourself personally have or have not received help at the college. Please make one check for each item listed below in the appropriate column.

E X A P L E

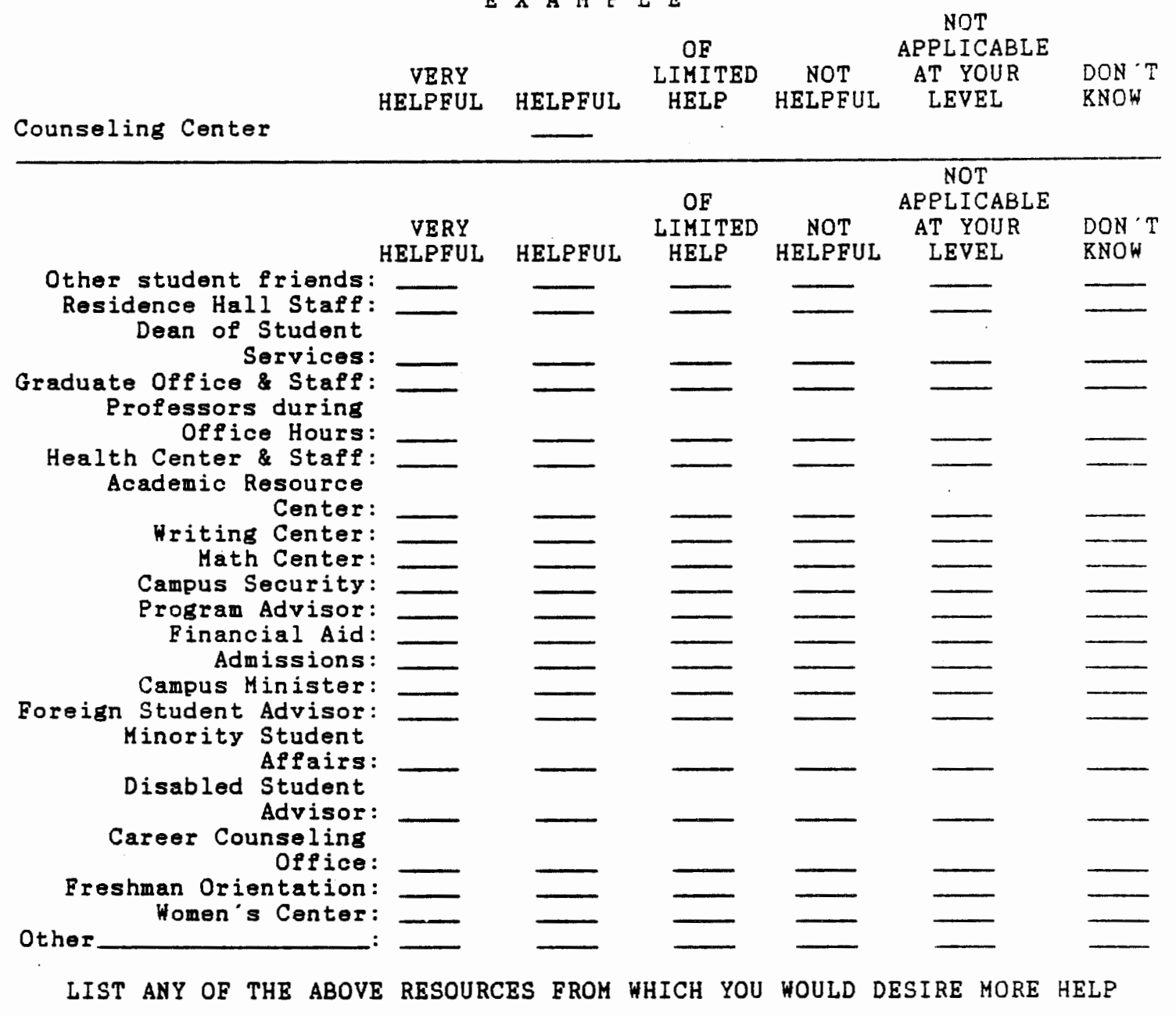




\section{SURVEY OF SERVICES FOR STUDENTS}

Southern Oregon State College, 1996

DIRECTIONS: PLEASE PUT A CHECR MARR NEXT TO THE APPROPRIATE RESPONSES.

Present residence College housing Commuter

Are you a

Freshman
Sophomore
Junior
Senior
Graduate student

Gender

$$
\text { Female }
$$$$
\text { Male }
$$

Age

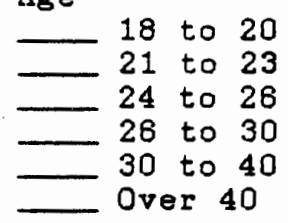

How long have you attended the college?

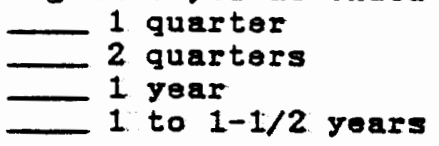

\section{Are you currently employed
More than 20 hours/week
Less than 20 hours/week \\ Are you currently employed
More than 20 hours/week
Less than 20 hours/week \\ Are you currently employed
More than 20 hours/week
Less than 20 hours/week - Not at all}

$1-1 / 2$ to 2 years

2 to 3 years

- 3 to 4 years

- Over 4 years

Ara you currently a Full-time student

How involved are you in extracurricular activities at the college?

Very involved

Somewhat involved Uninvolved

What is your major?

Are you an American citizen a permanent imnigrant an international student 
If you are a permanent immigrant or an international student, please answer the following questions. All answers will be anonymous.

What is your native language?

What country are you from?

Did you take the TOEFL?

no, I did not

yes, I did. My last score was:

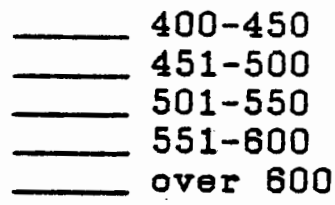

How would you describe your English ability?

Circle one number to show how good your skills are in each area.

\begin{tabular}{lllll} 
& Poor & & \multicolumn{3}{c}{ Good } \\
Understanding lectures & 1 & 2 & 3 & 4 \\
Understanding conversations & 1 & 2 & 3 & 4 \\
Making class presentations & 1 & 2 & 3 & 4 \\
Taking part in conversations & 1 & 2 & 3 & 4 \\
Reading textbooks & 1 & 2 & 3 & 4 \\
Writing papers and essays & 1 & 2 & 3 & 4 \\
Taking Tests & 1 & 2 & 3 & 4 \\
Taking Notes & 1 & 2 & 3 & 4
\end{tabular}


APEENDIX B

RESPONDENT DEBRIEFING LAETTER 
I hope that you will agree to take part in this researoh project on assessing needs for student services at Southern Oregon State College. This study involves a questionnaire where yur responsess will be anonymous and nothing will be known about your icentify beyond general demographic data. This questionnaire is being given in this class by a prior agreed arrangement between your instructor and myself. Your involvement is wholly voluntary and you may refuse to participate without affecting your class status. You should understand that agreeing to participate in the questionnaire does not commit you to any further involvement in the study and that you will not be contacted again.

The purpose of the study is to assess the extent of the use of student services by both American and international students at. Soluthern Oregon State College. The elements to be assessed include how important you think philosophical objectives of student services are, how well you think those objectives are met by student services providers, and if there is a resultant need for services based on a cross-index of these responses. You will also be asked to identify which student services are helpful to you. A compilation of demographic data about respondents will help me to determine which groups are being well-served and well-informed. I will provide this information to the college after I have finished my analysis of the data. The finished product will be submitted as a master's thesis at Portland State University in the Department of Applied Linguistios.

You can contact me at (541) 474-6457 if you have any questions or concerns about this questionnaire or how the information will be used. All information gathered will be kept in confidence, no names of individuals will be involved in this study, and after this study is finished all questionnaires will be destroyed.

You should understand that you will receive no remuneration from this study, no positive influence on your class grade, and no benefit beyond any concepts suggested through the questionnaire, but that it may be of benefit to others in the future. Furthermore, taking part in this questionnaire will not affect your relationship with Southern Oregon State College, any other school, or any other official agency in any way.

Thank you for your willingness to be a part of this study.

\section{Molly Emmons}

If you have concerns or questions about this study, please contact the Chair of the Human Subjects Research Review Committee, Research and Sponsored Projects, 105 Neuberger Hall, Portland State University, 503/725/3417. 
APEENDIX C

DEMOGRAPHIC DATA 
TABLE XIV

AMERICAN AND INTERNATIONAI DEMOGRAPHIT DATA

Ameriean International

Present Residence

College Housing $25 \quad 15$

Commuter $\quad 66 \quad 33$

Missing $\quad 3 \quad 4$

Gender

Male $\quad 57 \quad 21$

Female $\quad 34 \quad 26$

Missing 4

Are you a

Erestuman $\quad 25 \quad 20$

Sophomore $25 \quad 5$

Junior $16 \quad 8$

Senior $19 \quad 6$

Graduate Student $\quad 4 \quad 10$

Missing $\quad 6 \quad 4$

Age

18 to $20 \quad 35 \quad 14$

21 to $23 \quad 2$

24 to $26 \quad 8$

27 to $30 \quad 10$

31 to $40 \quad 3 \quad 5$

Over $40 \quad 301$

Missing 4

How long have you attended this college?

1 guarter

2 guarters $\quad 24 \quad 19$

1 year

1 to $1-1 / 2$ years

$16-14$

$1-1 / 2$ to 2 years

4

18

2 to 3 years

$10-6$

3 to 4 years

$13-3$

Over 4 years

Missing

5

Are you currently employed

More than $20 \mathrm{hrs} /$ week $\quad 32$

Less than $20 \mathrm{hrs} /$ week $\quad 24$

Not at all $\quad 35 \quad 23$

Missing 44 
TADLE XIV (oOtinued)

Are you currently a.

Full time student

Part time student

82

7

Missing

28

31

12

10

How involved are you in extracurricular activities at the college?

Very involved

14

Somewhat involved

26

Uninvolved

52

Missing

3

6

29

15

3

Are you

an American citizen

a permanent immigrant

91]

1

1

an international student

missing

0

10

4

41

What is your major?

American: (in ranking order)

Undeclared

History

Business

Criminology

(10)

Economics

International Studies

Biology

Geography

Health/Promotion

Marketing

Accounting

(4)

(4)

(4)

Chemistry

Communications

Education

Environmental Science (2)

MBA

Psychology

Political Science

Anthropology

Art

Computer Science

English

Mathematics

Music

Physics

Pre-Physical Therapy

Sociology

(1)

Theater 
TAPLE XIV (cont.)

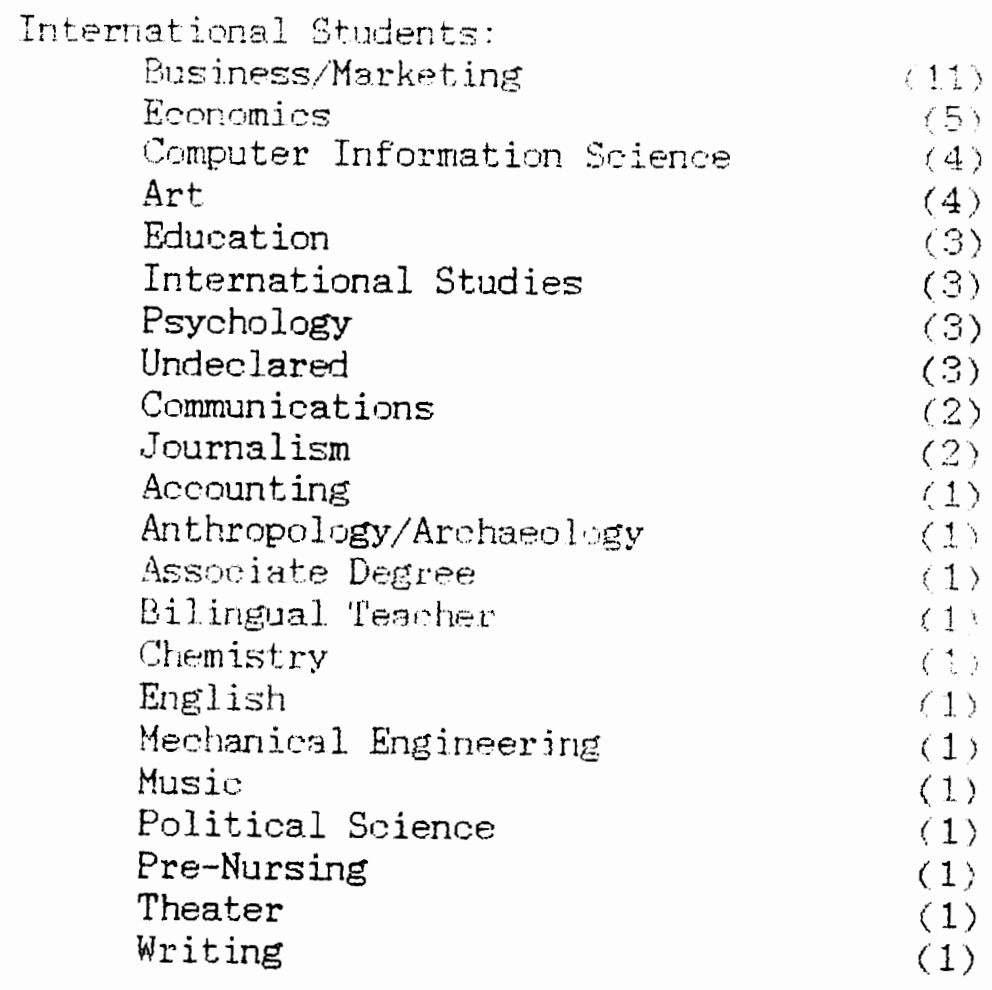

For international students only:

What is your native language?

Spanish

Tapanese

Indonesian

Chinese

Erench

Vietnamese

Arabic

Ethiopian

Korean

Palauan

Polish

Russian

Serbian

(i)

Swahili

(1)

Missing

(1)

(4) 
What country are you from?

Japan
Mexico
Indonesia
Spain
France
Taiwan
Vietnam
Ethiopia
Korea
Palau
Peru
Poland
Russia
United Arab Emirates
Yugoslavia (!)
Zaire
Missing

Did you take the TOEFL?

$$
\begin{aligned}
& \text { No, I did not } \\
& \text { Yes, I did } \\
& \text { Missing }
\end{aligned}
$$

$$
\begin{gathered}
\text { My last score was: } \\
400-450 \\
451-500 \\
501-550 \\
551-600 \\
\text { over } 600
\end{gathered}
$$

How would you describe your English ability?

Poor

Goord

Understanding lectures

Understanding conversations

Making class presentations

Taking part in conversations

Reading textbooks

Writing papers and essays

Taking tests

Taking notes

$\begin{array}{rrrr}0 & 7 & 23 & 21 \\ 1 & 7 & 15 & 28 \\ 7 & 17 & 17 & 9 \\ 1 & 16 & 18 & 15 \\ 0 & 7 & 28 & 15 \\ 6 & 8 & 26 & 10 \\ 1 & 11 & 24 & 14 \\ 2 & 15 & 19 & 14\end{array}$


Addendum:

Demographic data from Section II of Student Services Questionnaire: List any of the Above Resources From Which You Would Desire More Help:

Americans International

Financial Aid

Career Counseling

Professors

Health Center

Foreign Student Advisor

Writing Center

Minority Student Advisor

Freshman Orientation

(2)

Math Center

(0)

Academic Advising

Academic Resource Center

Program Advisor

Campus Security

Residence Halls

Women's Center

Admissions

Dean of Student Affairs

Other requests:

Americans:

$$
\begin{aligned}
& \text { "personal counseling" } \\
& \text { "science tutoring" } \\
& \text { "intro to tutoring" }
\end{aligned}
$$

International students:

"everything except friends" 